\title{
MICAPIPE: A PIPELINE FOR MULTIMODAL NEUROIMAGING AND CONNECTOME ANALYSIS
}

Raúl R. Cruces*1, Jessica Royer*1,2, Peer Herholz ${ }^{3}$, Sara Larivière ${ }^{1}$, Reinder Vos de Wael ${ }^{1}$, Casey Paquola ${ }^{1}$, Oualid Benkarim ${ }^{1}$, Bo-yong Park ${ }^{1,4,5}$, Janie Degré-Pelletier ${ }^{6}$, Mark Nelson ${ }^{7}$, Jordan DeKraker ${ }^{1}$, Christine Tardif ${ }^{7}$, Jean-Baptiste Poline ${ }^{7}$, Luis Concha ${ }^{8}$, Boris C. Bernhardt ${ }^{1}$

${ }^{I}$ Multimodal Imaging and Connectome Analysis Lab, McConnell Brain Imaging Centre, Montreal Neurological Institute, McGill University, Montreal, Québec, Canada. ${ }^{2}$ Analytical Neurophysiology Laboratory, Montreal Neurological Institute, McGill University, Montreal, Québec, Canada. ${ }^{3}$ NeuroDataScience - ORIGAMI lab, McConnell Brain Imaging Centre, Montreal Neurological Institute, McGill University, Montreal, Québec, Canada. ${ }^{4}$ Department of Data Science, Inha University, Incheon, Republic of Korea. ${ }^{5}$ Center for Neuroscience Imaging Research, Institute for Basic Science, Suwon, Republic of Korea. ${ }^{6}$ Université du Québec à Montréal, ${ }^{7}$ McConnell Brain Imaging Centre, Montreal Neurological Institute, McGill University, Montreal, Québec, Canada ${ }^{8}$ Instituto de Neurobiología, Universidad Nacional Autónoma de México, Campus Juriquilla.

*co-first authors

\section{Corresponding authors}

Raul R. Cruces, PhD

Email: raul.rodriguezcruces@mcgill.ca
Boris C. Bernhardt, $\mathrm{PhD}$

Email: boris.bernhardt@mcgill.ca 


\begin{abstract}
Multimodal magnetic resonance imaging (MRI) has accelerated human neuroscience by fostering the analysis of brain structure, function, and connectivity across multiple scales and in living brains. The richness and complexity of multimodal neuroimaging, however, demands processing methods to integrate information across modalities and different spatial scales. Here, we present micapipe, an open processing pipeline for BIDS-conform multimodal MRI datasets. micapipe can generate i) structural connectomes derived from diffusion tractography, ii) functional connectomes derived from resting-state signal correlations, iii) geodesic distance matrices that quantify cortico-cortical proximity, and iv) microstructural profile covariance matrices that assess inter-regional similarity in cortical myelin proxies. These matrices are routinely generated across established 18 cortical parcellations (100-1000 parcels), in addition to subcortical and cerebellar parcellations. Results are represented on three different surface spaces (native, conte69, fsaverage5), and outputs are BIDS-conform. Processed outputs can be quality controlled at the individual and group level. micapipe was tested on several datasets and is available at https://github.com/MICA-MNI/micapipe, documented at https://micapipe.readthedocs.io/, and containerized as a BIDS App http://bids-apps.neuroimaging.io/apps/. We hope that micapipe will foster robust and integrative studies of human brain microstructure, morphology, and connectivity.
\end{abstract}

\title{
KEYWORDS:
}

Multimodal | MRI | Connectome | Neuroimaging | Multiscale | BIDS 


\section{INTRODUCTION}

The human brain is a highly complex network organized across multiple spatial and temporal scales (Betzel and Bassett 2017). Neuroimaging, and in particular magnetic resonance imaging (MRI), provides versatile contrasts sensitive to the brain's microstructure, connectivity, and function, offering a window into its organization in living humans (Turner, 2019; Larivière et al., 2019; van den Heuvel et al., 2019; Van Essen et al., 2013).

Recent years have witnessed multiple neuroimaging data acquisition efforts (Gordon et al., 2017; Royer et al., 2021; Van Essen et al., 2012) as well as initiatives for open data sharing to promote transparency and reproducibility (Milham et al., 2018). These initiatives offer researchers the ability to interrogate brain structure and function in thousands of individuals across multiple sites from around the world. In addition, a variety of processing pipelines has previously been developed. These include tools for the automated analysis of cortical/subcortical morphology based on T1-weighted MRI (Fischl, 2012; Kim et al., 2005; Patenaude et al., 2011), approaches for the analysis of myelin-sensitive MRI contrasts to assess brain microstructure (Paquola et al., 2019b; Glasser and Van Essen, 2011; Waehnert et al., 2016), the study of intrinsic brain function and functional connectivity via resting-state functional MRI, rsfMRI (Biswal et al., 2010; Craddock et al., 2013; Esteban et al., 2019), and analysis of structural connectivity inferred via diffusion MRI tractography (Cieslak et al., 2021; Daducci et al., 2012; Tournier et al., 2019). Individually, ongoing advances in MRI modelling approaches result in increasing biological validity (Craddock et al., 2015; Jbabdi et al., 2007; Mars et al., 2021), promising to extend findings and theory from classical neuroanatomy in non-human animals to humans. Yet, as most tools generally focus on the processing of individual modalities, or the combination of at most two different modalities (e.g. T1-weighted MRI and rs-fMRI), researchers interested in additional synergies across an even larger catalogue of modalities are forced to develop custom-built image co-registration and data-integration procedures.

System neuroscience has increasingly benefitted from paradigms that combine different imaging modalities (Paquola et al., 2020; Van den Heuvel et al., 2019; Van den Heuvel and Yeo, 2017). For example, multiple studies have begun to study brain function and functional connectivity in surfacebased anatomical reference frames (Huntenburg et al., 2021; Tierney et al., 2013; Vos de Wael et al., 2018), and combined these assessments with diffusion MRI approaches (Liu et al., 2016; Hong et al., 2019). Further work integrating structural and functional neuroimaging modalities has propelled interest in examining structure-function relationships in the human brain (Huntenburg et al., 2018; Suárez et al., 2020; Benkarim et al., 2021; Paquola et al., 2019b; Vázquez-Rodríguez et al., 2019). Furthermore, there has been significant development towards the identification of multimodal parcellations (Fan et al., 2016; Eickhoff et al., 2018; Genon et al., 2021, 2018; Glasser et al., 2016) and large-scale gradients of brain organization (Vos de Wael et al., 2020, 2021; Margulies et al., 2016; Paquola et al., 2020, 2019a, 2019b; Valk et al., 2020; Müller et al., 2020; Tian et al., 2020).

To build upon existing MRI processing pipelines that are primarily geared towards single modalities, we developed micapipe (http://micapipe.readthedocs.io). The pipeline integrates advanced processing streams for structural MRI, resting-state functional MRI (rs-fMRI), diffusion-weighted MRI, and myelin-sensitive MRI to automatically generate models of structural, functional, and microstructural human brain organization. Micapipe generates inter-regional matrices across different spatial scales, using several cortical as well as subcortical parcellations (Desikan et al., 2006; Destrieux et al., 2010; Scholtens et al., 2018; von Economo, 2009; Fischl, 2012; Vos de Wael et al., 2020; Schäfer et al., 2018; Glasser et al., 2016; Patenaude et al., 2011; Diedrichsen et al., 2009). In a nutshell, micapipe transforms 
bioRxiv preprint doi: https//doi.org/10.1101/2022.0131.478189; this version posted February 2, 2022. The copyright holder for this preprint (which was not certified by peer review) is the author/funder, who has granted bioRxiv a license to display the preprint in perpetuity. It is made available under aCC-BY 4.0 International license.

BIDS-conform MRI data (Gorgolewski et al., 2017) to processed macroscale connectomes in an easyto-analyze format. Easy-to-verify outputs and visualizations can be produced for quality control (QC). In addition to its codebase being openly available on GitHub (http://github.com/MICA-MNI/micapipe), micapipe is also available as a container (Docker, included as BIDS App), and is accompanied by detailed tutorials and documentation.

\section{RESULTS}

Micapipe has a modular workflow that can incorporate multiple MRI data modalities (T1-weighted MRI, myelin-sensitive MRI, diffusion-weighted MRI, and resting-state functional MRI), converting BIDS-conform input into BIDS-conform surface, volume, and matrix data (FIGURE 1A). The following sections describe key pipeline features, main outputs, and detail automated quality control (QC) visualizations. We also perform several validation experiments across a diverse range of datasets.

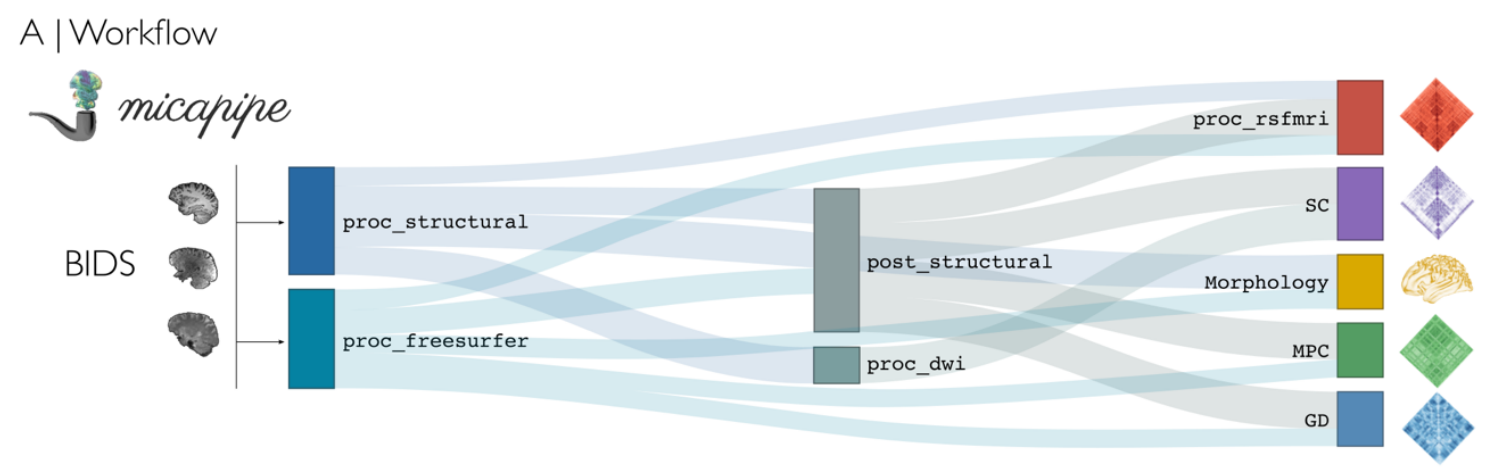

B | Pipeline outputs

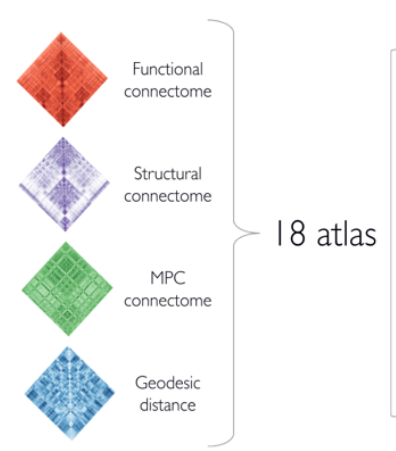

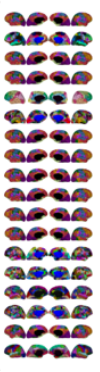

C | Organization
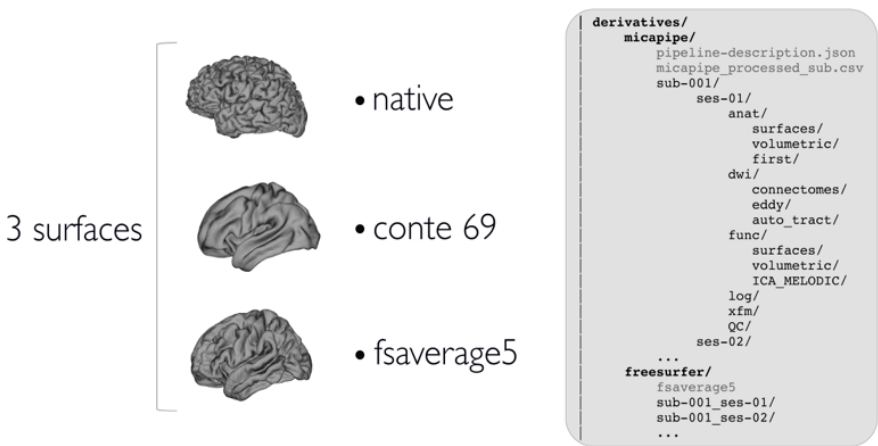

Figure 1. A) Pipeline workflow. B) Outputs can be generated across 18 different cortical parcellations (100-1000 parcels), in addition to subcortical and cerebellar parcellations. Most results are mapped to three different surface spaces: native, conte69 and fsaverage5. C) Outputs are hierarchically ordered with BIDS-conform naming.

\subsection{Pipeline workflow}

Processing modules of micapipe can be run individually or bundled using specific flags via a commandline interface. Multimodal integration relies strongly on characterization of anatomy via the processing of T1-weighted MRI data. Using volume and surface-based processing streams, subcortical, cortical and cerebellar segmentations are generated in subject- and modality-specific spaces. Using structural imaging data, in addition to other input modalities, inter-regional brain matrices can be generated across 18 combinations of cortical, subcortical, and cerebellar parcellations. Inter-regional matrices are: i) structural connectomes (SC) derived from diffusion tractography (Smith et al., 2015a), ii) functional connectomes (FC) derived from resting-state signal correlations (Biswal et al., 2010), iii) geodesic 
distance (GD) matrices that quantify cortico-cortical proximity using cortical surface models (Ecker et al., 2013; Hong et al., 2018), and iv) microstructural profile covariance (MPC) matrices that assess inter-regional similarity in intracortical intensity profiles from microstructurally-sensitive imaging (Paquola et al., 2019b). Surface-mapped features are made available across three surfaces (Figure 1B): native, conte69 (Van Essen et al., 2012), and fsaverage5 (Fischl et al., 1999). Intermediary files and processed derivatives and matrices conform to BIDS naming conventions (FIGURE 1C), facilitating future use and harmonization across datasets and software.

\subsection{Quality control (QC)}

The QC module visualizes outputs at the individual and group levels (FIGURE 2A). Reports detail completed processing steps, including image registrations, surface parcellations, and region-to-region matrices. They are organized by modality and parcellation. These reports help users to identify missing data, poor image quality, and faulty registrations (Figure 2A). Complementing subject-specific reports, group level QC automatically generates a report outlining completed and missing modules for each subject facilitating use for large datasets (FigurE 2B). 
bioRxiv preprint doi: https://doi.org/10.1101/2022.01.31.478189; this version posted February 2, 2022. The copyright holder for this preprint (which was not certified by peer review) is the author/funder, who has granted bioRxiv a license to display the preprint in perpetuity. It is made available under aCC-BY 4.0 International license.

\section{A I Individual QC}

Code example

$$
\text { mica-pipe -QC_sub -sub S01 -bids ./rawdata -out ./derivatives }
$$

Volume visualization
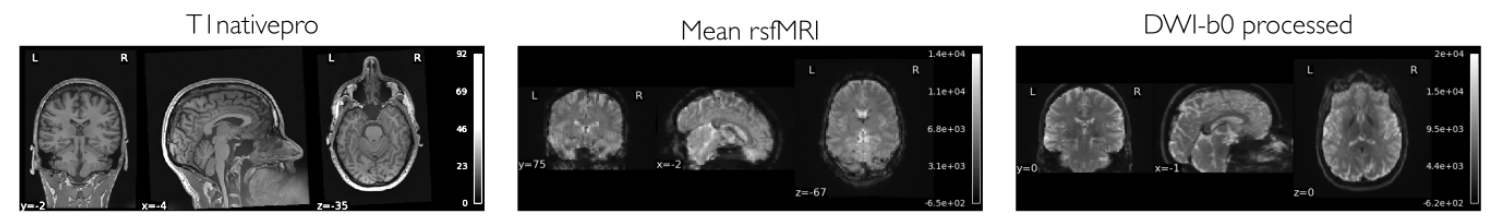

Registrations

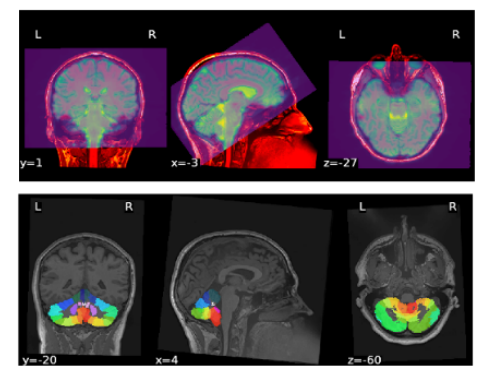

Surface parcellations

Volume to

volume

$\mathrm{ROI}$ to

volume

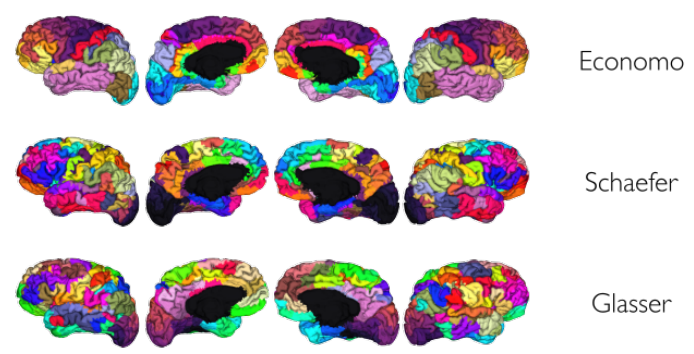

Matrix visualization

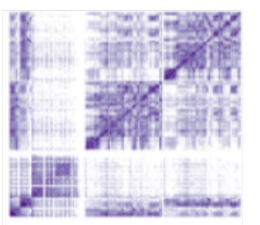

Structural connectome

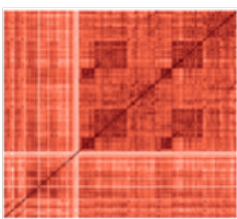

Functional connectome

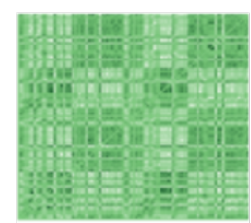

Microstructure profile covariance

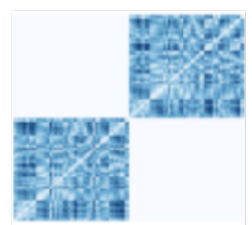

Geodesic distance

\section{B | Group/dataset QC}

Code example

mica-pipe -QC -out ./derivatives

\section{Output}

\section{Pipeline progress}

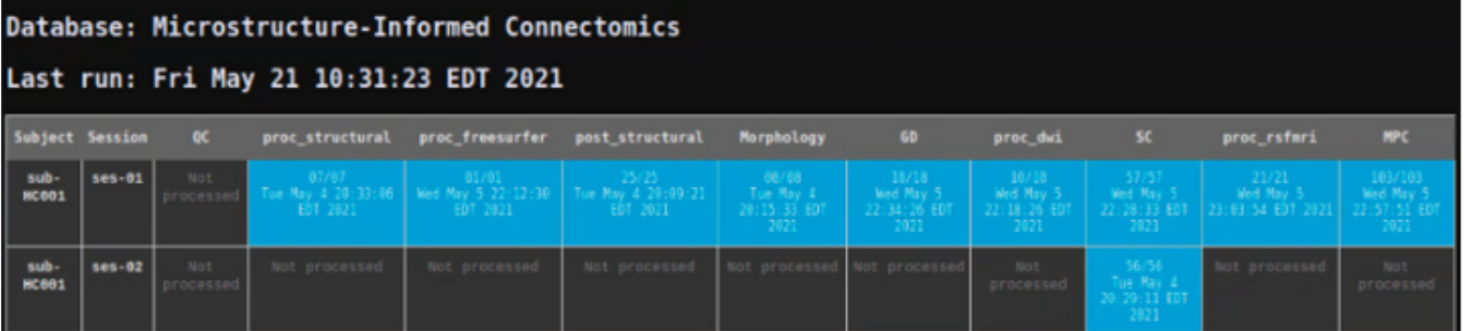

FIGURE 2. A) Individual level quality control (QC), which can be run at any point during the processing. The QC procedure will generate a html report file for each subject containing visualizations of intermediate files for volume visualization, crossmodal co-registrations, and surface parcellations. Moreover, it allows inspection of inter-regional matrices such as the structural connectome (from diffusion MRI tractography), the functional connectome (from resting-state fMRI signal correlation), the microstructural profile covariance matrix (from correlations of intracortical microstructural profiles), and geodesic distance matrices. B) QC can also be run at a group/dataset-level. The report consists of a color-coded table with rows as subjects and columns as the pipeline modules (blue: completed, orange: incomplete/error, dark gray: not processed). 
bioRxiv preprint doi: https://doi.org/10.1101/2022.01.31.478189; this version posted February 2, 2022. The copyright holder for this preprint (which was not certified by peer review) is the author/funder, who has granted bioRxiv a license to display the preprint in perpetuity. It is made available under aCC-BY 4.0 International license.

\subsection{Assessing output consistency within and between datasets}

We evaluated whether micapipe yields consistent results across 50 individuals of an openly available multimodal MRI dataset [MICA-MICs; (Royer et al., 2021), and also compared processed outputs to those from six additional datasets (TABLE S1).

A | Connectome meassurements

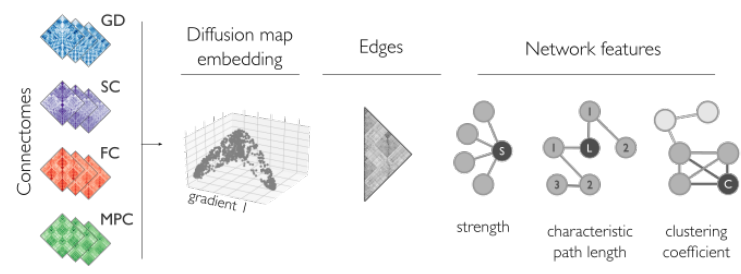

C | Within dataset stability for other datasets
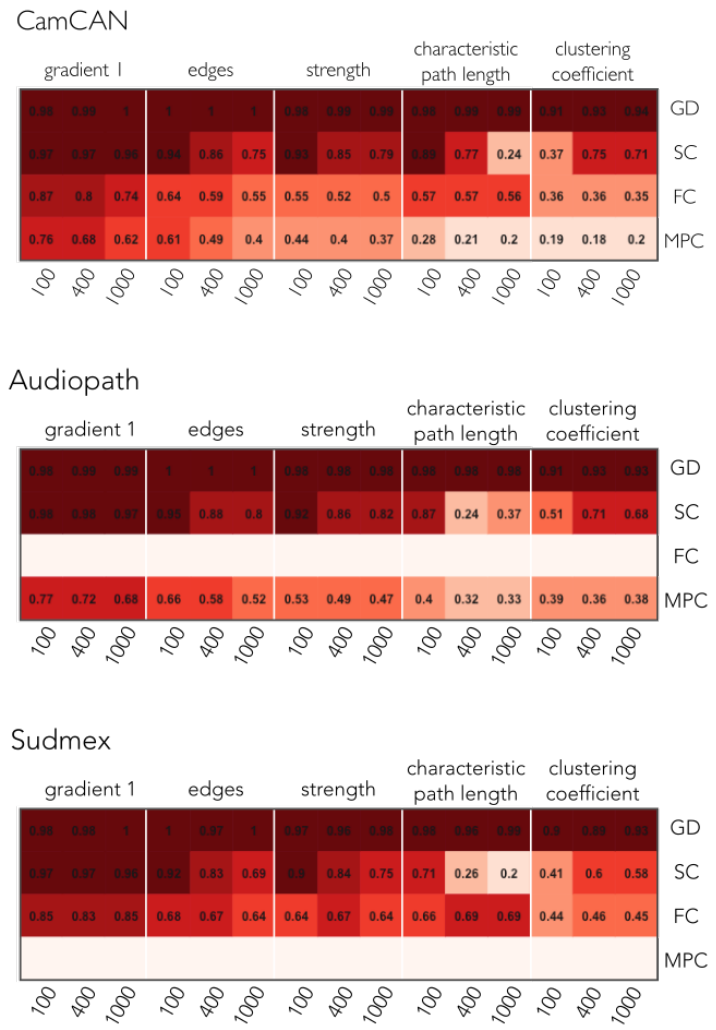

B | Within dataset stability for MICs
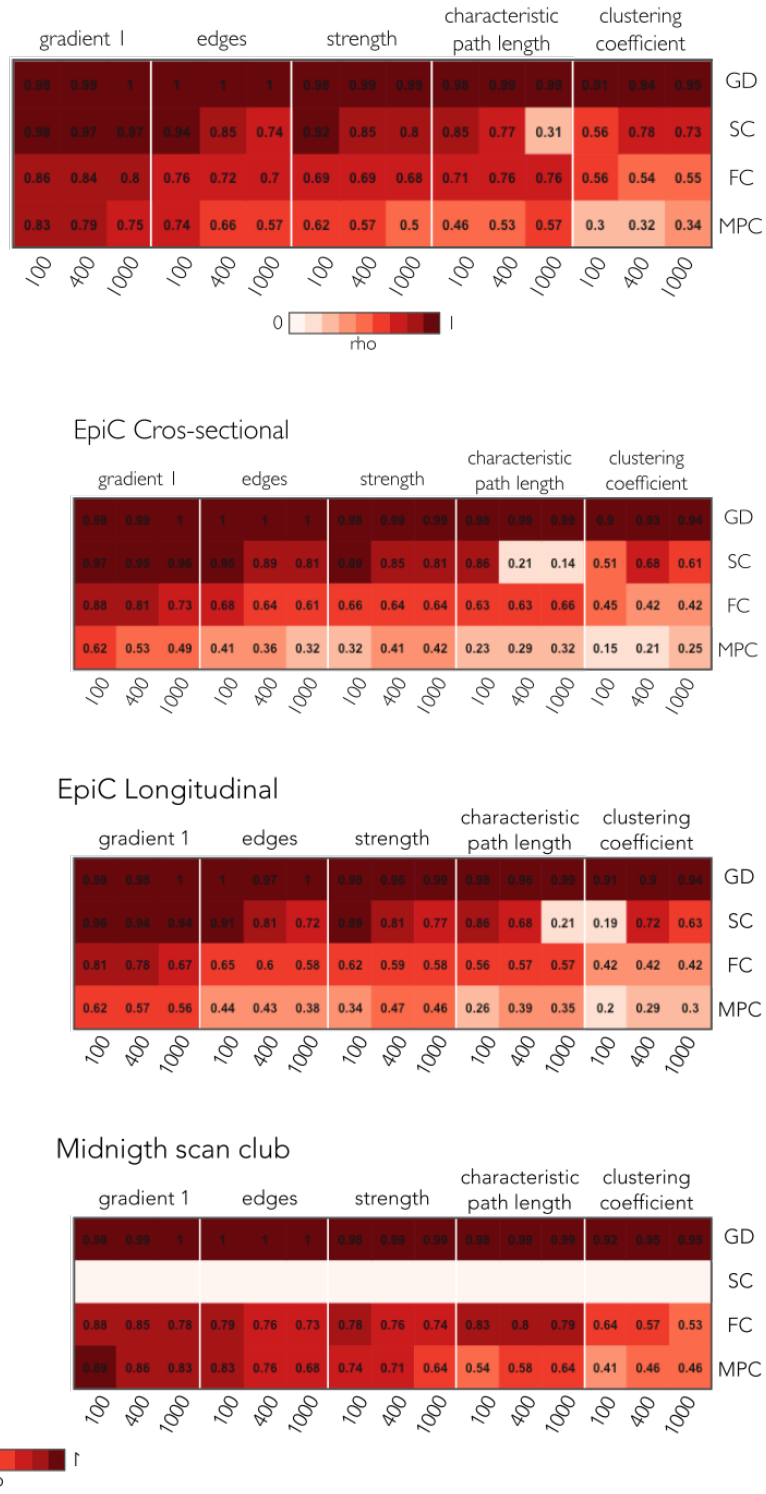

FIGURE 3. Mean consistency value, indicating the Spearman's rho between subject- and the group-level measurements, for the Schäfer-100, Schäfer-400 and Schäfer-1000 parcellations. A) For each modality, five measurements were evaluated: principal gradient, edges, node strength, path length, and clustering. Empty rows indicate modalities that were not analyzed. MPC: microstructural profile covariance, FC: functional connectivity, SC structural connectivity, GD geodesic distance

We first assessed within-dataset consistency for each modality (GD, SC, FC, MPC) at three different granularities (Schäfer 100, 400 and 1000 parcels) using five different metrics. We generated modalityand dataset-specific mean group matrices and computed consistency across the following features: the first eigenvector/gradient explaining the most data variance (calculated via diffusion map embedding (Coifman et al., 2006)), the matrix edges, as well as node strength, characteristic path length, and clustering coefficient as three representative graph features (Rubinov and Sporns, 2010), Figure 3A]. We correlated subject-level and group-level metrics to quantify within-dataset consistency (Spearman's 
bioRxiv preprint doi: https://doi.org/10.1101/2022.01.31.478189; this version posted February 2, 2022. The copyright holder for this preprint (which was not certified by peer review) is the author/funder, who has granted bioRxiv a license to display the preprint in perpetuity. It is made available under aCC-BY 4.0 International license.

rho, see Supplementary Figure 3A). Correlations were highest for GD and SC, followed by FC and MPC. Gradient 1 was the most consistent measure across parcellations and modalities, followed by edges and node strength. Overall, characteristic path length and clustering coefficient were similar at lower granularity (100 parcels) but increasingly dissimilar at higher granularity (1000 parcels). Findings were consistently observed across all datasets (FiguRE 3B-C).
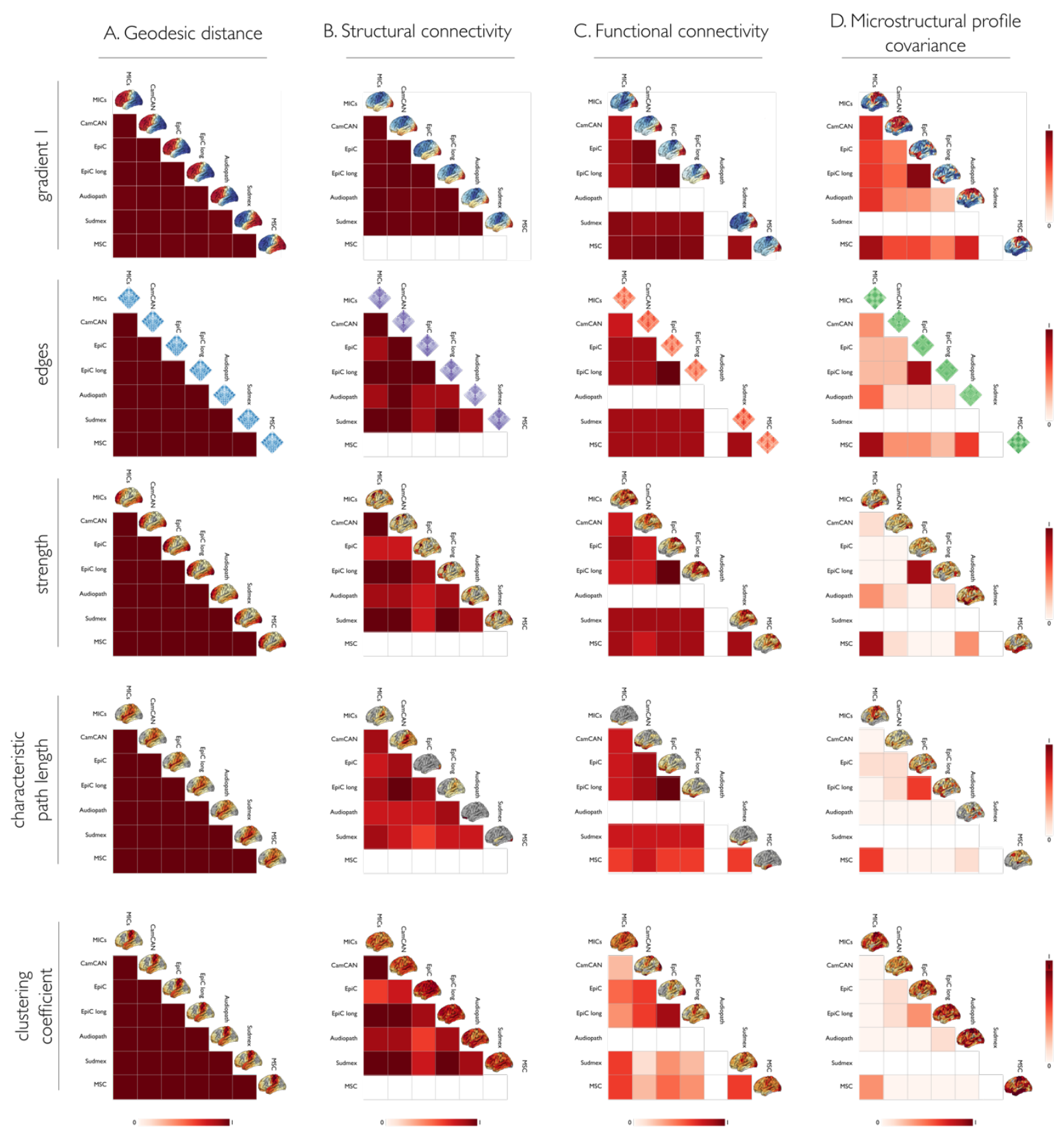

FIGURE 4. We assessed consistency of matrix parameters across datasets using Spearman's rho correlation coefficient for the same features as in Figure 3. Each column represents the different modality connectomes: A) geodesic distance, B) structural connectome, C) functional connectome, and D) microstructural profile covariance.

We also compared between datasets (Figure 4). As for the within-dataset analysis, we found the highest consistency between datasets for GD and SC, followed by FC and MPC. GD, SC and FC showed high similarity between datasets for the edges, first eigenvector/gradient, and node strength. FC had decreased consistency between datasets for characteristic path length and clustering coefficient. MPC had the lowest between dataset consistency for all measurements. 


\subsection{Performance}

We tested micapipe on seven different databases acquired using different MRI sequence/parameter combinations (TABle S1). Processing times varied depending on the image resolution, the need to additionally process data using FreeSurfer, the number of streamlines selected for the structural connectome generation, and the type of acquisitions per dataset (TABLE S2). Processing was performed on the Brain Imaging Center (BIC) cluster of the Montreal Neurological Institute and Hospital on Ubuntu 18.04.5 LTS version workstations. A maximum virtual memory of 6GB, with 6-10 CPU cores, and $20 \mathrm{~GB}$ of RAM were required. Output size depended on image resolution and the length of the rsfMRI acquisitions (TABLE S3).

\subsection{Software and data availability}

An expandable documentation at https://micapipe.readthedocs.io describes installation, usage, pipeline steps, updates, extra features, and provides a series of ready-to-use tutorials. All code can be found at https:/github.com/MICA-MNI/micapipe, and is published under the General Public License 3.0. Micapipe is delivered as a docker container via BIDS-App [http://bids-apps.neuroimaging.io/apps/ (Gorgolewski et al., 2017)], and available on ReproNim [https://github.com/ReproNim/containers (Halchenko et al., 2021)]. Detailed steps to use the Docker container and to build a corresponding singularity container are available under the readthedocs documentation. Code for figures and tables can be found in the micapipe-supplementary GitHub repository (https://github.com/MICAMNI/micapipe-supplementary). 


\section{DISCUSSION}

We present micapipe, an open software package to integrate and process raw multimodal MRI data into a range of multiple measures of structural and functional human brain network organization. As a standalone and BIDS App, micapipe inputs and outputs BIDS-conform MRI data. Its outputs consist of derivative features across multiple parcellations, available in both surface- and volume-based reference spaces. Notably, micapipe outputs include measures of brain morphology, together with inter-regional matrices encoding cortico-cortical spatial proximity (based on geodesic distance analysis along cortical surfaces derived from T1-weighted MRI), intrinsic functional connectivity (based on rs-fMRI signal correlations), structural connectivity (derived from diffusion MRI tractography), and microstructural similarity (derived from intracortical profile covariance analysis of myelin-sensitive MRI) aggregated across 18 different cortical as well as subcortical/cerebellar parcellations. Given the complexity of multimodal processing and analysis, micapipe furthermore offers advanced functionalities for individual and group-level QC at different stages of processing as well as final outputs. As a unified tool to fuse and analyze multimodal neuroimaging data, micapipe offers neuroscientists a workflow to robustly interrogate human brain organization across multiple scales.

A range of pipelines have previously been developed to process MRI images from specific modalities, including tools for the generation of cortical and subcortical segmentations based on T1-weighted MRI data (Das et al., 2009; Fischl, 2012; Kim et al., 2005), pipelines to process functional MRI data (Craddock et al., 2013; Esteban et al., 2019), as well as tools for diffusion MRI data handling (Cieslak et al., 2021; Jenkinson et al., 2012; Tournier et al., 2019). Several workflows have furthermore been developed for connectome mapping (Daducci et al., 2012; Whitfield-Gabrieli and Nieto-Castanon, 2012), which allow users to examine structural and functional network architecture in a systematic manner. Building upon these developments, micapipe offers a unified framework for multimodal fusion and data processing. As such, it is similar in scope to the proposed Connectome Mapper tool (Daducci et al., 2012), although with notable differences. In particular, micapipe incorporates a stream for the surface-based mapping of intracortical myelin proxies and for the generation of microstructural profile covariance (Paquola et al., 2019b). A growing body of literature emphasizes the utility of myelinsensitive MRI analysis for cortical parcellation (Carey et al., 2018; Glasser and Van Essen, 2011; Granberg et al., 2017), to assess brain and cognitive development (Deoni et al., 2012; Whitaker et al., 2016; Lebel and Deoni, 2018; Paquola et al., 2019a), and to interrogate microstructural imbalances in common brain disorders (Cooper et al., 2019; Du et al., 2019; Bernhardt et al., 2018; Larivière et al., 2019). Recent work has shown that the analysis of covariance patterns of intracortical microstructural profiles can generate new descriptions of large-scale network organization (Paquola et al., 2020; Royer et al., 2020). These networks appear to be primarily governed by systematic shifts in laminar differentiation and neuronal density, showing a principal organizational axes similar to those at the level of cytoarchitecture and intrinsic functional connectivity (Margulies et al., 2016; Paquola et al., 2021, 2019b). A further notable feature is the automated generation of cortico-cortical geodesic distance matrices, which indexes proximity between different regions on the folded cortical surface. Corticocortical geodesic distance has been suggested to relate to intrinsic, horizontal connectivity within the cortical ribbon as well as to cortical wiring cost (Ecker et al., 2013; Hong et al., 2018; Paquola et al., 2020). Moreover, several investigations into principles of macroscale brain organization have emphasized that the brain is a physically embedded network, and that thus inter-regional distance relationships may help in the understanding of the topographic layout of functional systems and the connections formed between them (Betzel et al., 2016; Betzel and Bassett, 2018; Margulies et al., 2016; Valk et al., 2020; Wang et al., 2021; Smallwood et al., 2021). 
A series of evaluations assessed consistency of micapipe outputs, studying data from 455 individuals across seven datasets. Our evaluations focused on the consistency of inter-regional matrix edges, the first eigenvector (gradient), and three widely used graph theoretical measurements (node strength, characteristic path length, clustering coefficient) for up to four matrix modalities (i.e., geodesic distance, functional connectivity, structural connectivity, microstructural covariance). Altogether, our results indicate a generally high consistency of the first gradient across datasets, with some variations across modalities. For example, geodesic distance and structural connectivity gradients were markedly consistent ( $r>0.95)$, followed by functional connectivity and microstructural profile covariance. It is likely that functional connectivity measures and associated gradients may, in part, be influenced by state-to-state variations compared to the more static measures of structural connectivity and geodesic distance, likely in addition to data acquisition related effects. Edges and graph derived measurements followed an analogous pattern of consistency. With respect to the relatively low stability of microstructural profile covariance, one needs to highlight that the included datasets greatly varied in terms of microstructurally sensitive MRI contrasts, featuring T1-weighted/T2w intensity ratio (Glasser and Van Essen, 2011), quantitative T1 relaxometry (Royer et al., 2021), as well as magnetization transfer imaging (Shafto et al., 2014). While these sequences are all though to be sensitive to intracortical myelin content, their individual biophysical specificity remains to be established.

Through the successful integration of several processing tools, micapipe provides multiple ready to use inter-regional feature matrices, i.e., structural connectomes, functional connectomes, microstructural covariance, and geodesic distance, together with QC procedures. Our pipeline is supported by a growing ecosystem of open tools for data and code sharing, notably Github, readthedocs, Docker, BIDS Apps (Gorgolewski et al., 2017), and repronim/datalad (Robert et al., 2016). By making micapipe openly accessible as well, we hope that it will be beneficial for future studies on human brain organization. 


\section{MATERials AND Methods}

Micapipe runs modular processing streams on BIDS-conform raw T1-weighted, microstructuresensitive, diffusion-weighted, and resting-state functional MRI data to generate fully processed surface/volume features as well as inter-regional feature matrices. A documentation with detailed descriptions on the installation, implementation, as well as usage examples and output files are available at https://micapipe.readthedocs.io/.

\subsection{Workflow and main processing modules}

Micapipe requires the input dataset to be formatted in BIDS (Gorgolewski et al., 2016).

\section{Structural processing}

Structural processing operates on T1-weighted images. The structural processing workflow can perform volumetric (with command-line option: -proc_structural) and surface-based (-proc_freesurfer, post_structural, -GD, -Morphology) processing. The workflow registers subject data to volumetric and surface-templates providing several useful structural metrics for further analyses. These include geodesic distance matrices (-GD) mapped to multiple parcellation schemes as well as vertex-wise cortical thickness and curvature data (-Morphology). The structural workflow includes tools from AFNI (Cox, 1996), FSL (Jenkinson et al., 2012), ANTs (Avants et al., 2011), Mrtrix3 (Tournier et al., 2019) and FreeSurfer (Fischl, 2012). Further information about the usage and outputs is found in the structural processing section in the online documentation.

\section{Proc structural}

Initial structural pre-processing (i.e.,-proc_structural) keeps all data in volumetric format and generates a T1-weighted image in native processing space (nativepro, Figure S1A). Each T1-weighted run is reoriented to LPI orientation (i.e., left-right, posterior-anterior, inferior-superior), de-obliqued, and oriented to standard space (MNI152). If multiple T1-weighted scans are found in the raw data, they are linearly aligned to the first run and averaged. Next, the average image is corrected for intensity nonuniformity (N4, Tustison et al., 2010) and intensity is normalized between 0 and 100. The resulting image is named T1 nativepro, which stands for $\boldsymbol{T} 1$-weighted in native processing space. T1 nativepro is skull-stripped, subcortical structures are segmented using FSL FIRST (Patenaude et al., 2011), and tissue types are classified (gray matter, white matter, CSF) using FSL FAST (Zhang et al., 2001). A non-linear registration to MNI152 (0.8mm and 2mm resolutions) is calculated (Tustison and Avants, 2013) and a five-tissue-type (5TT) image segmentation is generated for anatomically constrained tractography.

\section{Proc freesurfer}

Cortical surface segmentations are generated from native T1-weighted scans using FreeSurfer 6.0 (Fischl, 2012) and ordered under the FreeSurfer directory, following BIDS naming conventions. We provide an option for datasets that have already been quality controlled to easily integrate the results within the pipeline's directory structure and an option to process with voxel sizes less than $1 \mathrm{~mm}^{3}$ at native resolution (-hires). We recommend that users carefully inspect and, if needed, manually correct FreeSurfer-generated cortical surface segmentations. As micapipe relies heavily on surface-based processing, poor segmentation quality may compromise downstream results.

\section{Post structural}

The first step of the post structural processing is to calculate an affine registration from native FreeSurfer space to TInativepro space. It then registers a probabilistic cerebellar atlas (Diedrichsen et 
al., 2009) from MNI152 to the subject's T1nativepro space using affine and non-linear transformations previously computed in the -proc_structural module. Next, a surface-based registration of fsaverage5 annotation labels to native surface is performed, and the surface-based parcellation in native FreeSurfer space is transformed into a volume. Finally, the transformation matrices are applied to bring each volumetric parcellation from native FreeSurfer space to Tlnativepro space. In the last step of this module, the pipeline builds a conte69-32k sphere and resamples white, pial and midthickness native surfaces to the conte69-32k template.

The -post_structural module registers native FreeSurfer-space cortical surfaces to two different standard templates (fsaverage5 and conte69), in addition to mapping all cortical parcellation schemes to the subject's native surface space and volumetric T1nativepro space (FIGURE S1B). Micapipe provides a total of 18 cortical, subcortical and cerebellar parcellations at different resolutions according to anatomical, cytoarchitectural, intrinsic functional, and multimodal schemes, at different resolutions. Anatomical atlases available in micapipe include Desikan-Killiany (aparc, Desikan et al., 2006) and Destrieux (aparc.a2009s, Destrieux et al., 2010) parcellations provided by FreeSurfer, as well as an in vivo approximation of the cytoarchitectonic parcellation studies of Von Economo and Koskinas (Scholtens et al., 2018). Additionally, we include similarly sized sub-parcellations, constrained within the boundaries of the Desikan-Killiany atlas, providing matrices with 100, 200, 300, and 400 cortical parcels following major sulco-gyral landmarks (Fischl, 2012; Vos de Wael et al., 2020). Parcellations based on intrinsic functional activity are also included across several granularities $(100,200,300,400$, $500,600,700,800,900$, and 1000 nodes, (Schäfer et al., 2018). Lastly, we also provide a multimodal atlas with 360 nodes derived from the Human Connectome Project dataset (Glasser et al., 2016). All atlases are provided on Conte69 and fsaverage5 surface templates, and on each participant's native surface to generate modality-specific matrices in subsequent modules.

\section{Morphology}

This module registers cortical thickness and curvature measurements to two distinct templates. Both surface-based morphological features are registered to fsaverage 5 and conte 69 and smoothed with a gaussian filter with full width half maximum of $10 \mathrm{~mm}$.

\section{GD: geodesic distance}

Individual GD matrices are computed along each participant's native cortical midsurface using workbench tools (Marcus et al., 2011). First, a centroid vertex is defined for each cortical parcel by identifying the vertex with the shortest summed Euclidean distance from all other vertices within its assigned parcel. Then, the geodesic distance is calculated from the centroid vertex to all other vertices on the midthickness mesh using Dijkstra's algorithm (Dijkstra, 1959). Notably, this implementation computes distances not only across vertices sharing a direct connection, but also across pairs of triangles which share an edge in order, thus mitigating the impact of mesh configuration on calculated distances. Vertex-wise GD values were averaged within parcels to improve computation performance.

\section{Diffusion-weighted imaging processing}

This section describes all DWI-related processing steps implemented in micapipe, which heavily rely on tools from MRtrix3 (Tournier et al., 2019). This includes image processing preparation for the construction of tractography-based structural connectivity matrices, as well as associated edge length matrices, all in native DWI space (FIGURE S1C). Micapipe DWI processing has been optimized for multishell DWI but can also handle single-shell data. Geometric and inhomogeneity corrections are performed in datasets that contain one or more reverse phase encoding DWI. It is a mandatory 
requirement that all DWIs have associated bvec, bval and json files, with encoded phase direction and total readout time.

\section{Proc $d w i$}

This module processes DWI scans, and derives several potentially useful metrics (e.g., fractional anisotropy, mean diffusivity, Figure S1C). First, if there is more than one set of DWI scans in the BIDS directory, they are aligned to each other using a rigid-body registration, and concatenated. All DWI images are then converted to Mrtrix Imaging format (mif), which encodes the bvec, bval, phase encoding direction and total readout time. Concatenated DWI images undergo denoising by estimating data redundancy in the PCA domain via a Marchenko-Pasteur approach [MP-PCA, (Veraart et al., 2016; Cordero-Grande et al., 2019)]. Then, Gibbs ringing artifact correction is applied (Kellner et al., 2016), and residuals are calculated from denoised images for QC purposes. Provided a reverse phase encoding, susceptibility distortion, head motion, and eddy currents are corrected (Andersson et al., 2003; Smith et al., 2004; Andersson and Sotiropoulos, 2016). If none is provided, only motion correction is performed. Additionally, outlier detection and replacement are applied (Andersson et al., 2016). After this step, the quality of the motion and inhomogeneity corrected diffusion images is assessed using eddy_quad (Bastiani et al., 2019), and a non-uniformity bias field correction (Tustison et al., 2010) is applied to finalize DWI preprocessing. Next, the b0 image is extracted from the corrected DWI and linearly registered to the main structural image (i.e., T1nativepro). A DWI brain mask is generated by registering the MNI152 brain mask to DWI space using previously generated transformations. A diffusion tensor model (Basser et al., 1994) is then applied to the corrected DWI and the fractional anisotropy and mean diffusivity images are computed (Veraart et al., 2013). An estimation of the response function is calculated over different tissues: cerebrospinal fluid, white matter, and gray matter (Dhollander, et al., 2016). These are later used to estimate the fiber orientation distribution (FOD) by spherical deconvolution (Jeurissen et al., 2014; Tournier et al., 2004). Next, intensity normalization is applied to each tissue FOD (Raffelt, et al., 2017). A second registration, in this case non-linear, is calculated between the normalized white matter FOD and the T1-weighted image previously registered linearly to DWI space. The resulting warp field allows for an improved registration between the T1-weighted and the native DWI space in most datasets. Finally, the 5TT segmentation image is registered to native DWI space and a gray matter white matter interface mask is calculated. For QC purposes, a track density image (Calamante et al., 2010) is computed with 1 million streamlines using the iFOD1 algorithm (Tournier et al., 2012) and anatomically constrained tractography (Smith et al., 2012).

\section{SC: structural connectome generation}

Structural connectomes are generated with Mrtrix3 from pre-processed DWI data from the previous module and subcortical and cerebellar parcellations are non-linearly registered to native DWI space. First, a tractography with 40 million streamlines (default but modifiable, maximum tract length $=400$, minimum length $=10$, cutoff $=0.06$, step $=0.5$ ) is generated using the $\mathrm{FOD} 2$ algorithm and 3-tissue anatomically constrained tractography (Smith et al., 2012; Tournier et al., 2010). A second tract density image (TDI) of the resulting tractography is computed for QC. By default, the full brain tractography is erased at the end of this module but can be kept using the option "-keep_tck". Next, spherical deconvolution informed filtering of tractograms [SIFT2 (Smith et al., 2015a)] is applied to reconstruct whole brain streamlines weighted by cross-sectional multipliers. The reconstructed cross-section weighted streamlines are then mapped to each parcellation scheme, with (i) cortical, (ii) cortical and subcortical, and (iii) cortical, subcortical, and cerebellar regions (Smith et al., 2015b. These are also warped to DWI native space. The connection weights between nodes are defined as the weighted streamline count, and edge length matrices are also generated. 


\section{Resting-state fMRI processing}

This module processes the rs-fMRI scans, in preparation for the construction of functional connectomes. This pipeline is optimized for spin-echo images with reverse phase encoding used for distortion correction. The pipeline is mainly based on tools from FSL and AFNI for volumetric processing, as well as FreeSurfer and Workbench for surface-based mapping (FIGURE S1D).

Initial fMRI processing steps involve the removal of the first five volumes to ensure magnetic field saturation, image re-orientation (LPI), as well as motion and distortion correction. Motion correction is performed by registering all time-point volumes to the mean volume, while distortion correction leverages main phase and reverse phase field maps acquired alongside rs-fMRI scans. Nuisance variable signal is removed either using an ICA-FIX classifier with a default training set or custom training set input by the user (Griffanti et al., 2014; Salimi-Khorshidi et al., 2014) or by selecting white matter, CSF, and global signal regression [for Discussion, see (Murphy et al, 2009, Murphy \& Fox 2017, Vos de Wael et al. 2017)]. Additionally, a regression of time points with motion spikes is performed using motion outlier outputs provided by FSL. Volumetric timeseries are averaged for registration to native FreeSurfer space using boundary-based registration (Greve and Fischl, 2009), and mapped to individual surface models using trilinear interpolation. Native-surface and template-mapped cortical time series undergo spatial smoothing (Gaussian kernel, FWHM $=10 \mathrm{~mm}$ ), and are subsequently averaged within nodes defined by several parcellation schemes. Parcellated subcortical and cerebellar time series are also provided and are appended before cortical time series.

\section{FC: functional connectome generation}

Individual rs-fMRI time series are mapped to individual surface models. Native surface-mapped time series are registered to standard surface templates (fsaverage5, conte69). Native surface and conte69mapped time series are averaged within cortical parcels. The subcortical and cerebellar parcellations are warped to each subject's native rs-fMRI volume space and used to extract the time series within each node. Individual functional connectomes are generated by cross correlating all nodal time series.

\section{Microstructural processing and microstructural profile covariance (MPC) matrix generation}

This module samples intracortical intensities from a quantitative MRI contrast, generating a depthdependent intracortical intensity profile at each vertex of the native surface mesh. By parcellating and cross-correlating nodal intensities, this module generates MPC matrices. This approach has been previously applied over the whole cortex (Paquola et al., 2019b), as well as in targeted structures such as the insula (Royer et al., 2020). The first processing step is a boundary-based registration from the quantitative imaging volume (default) or input microstructurally sensitive image contrast to FreeSurfer native space. Then, 16 equivolumetric surfaces (Waehnert et al., 2014) are generated between the pial, and white matter boundary previously defined from FreeSurfer. Intracortical equivolumetric surfaces are generated using https://github.com/kwagstyl/surface tools. Surfaces closest to pial and white matter boundaries are discarded to minimize partial volume effects, resulting in 14 surfaces. A surface-based registration is performed to fsaverage 5 and conte69-32k templates, and the vertex-wise intensity profiles are averaged within parcels for each parcellation. Nodal profiles are cross-correlated across the cortical mantle using partial correlations controlling for the average cortex-wide intensity profile. Several regions are excluded when averaging cortex-wide intensity profiles, including left/right medial walls, as well as non-cortical areas such as the corpus callosum and pericallosal regions. 


\subsection{Quality Control}

Micapipe includes an integrated QC module, which can be run at any point during processing. This step generates group-level and individual-specific QC reports allowing the user to identify missing files, verify registration performance, and check outputs requiring further inspection. Individual QC generates an html report with detailed information of each processing step (FigURE 2A). The report contains different tabs, one per module: main inputs and outputs of each module, main parameters of the processing steps (obtained from the metadata json sidecar files generated by micapipe), volume visualization of the main outputs, visualization of the main registrations, different surfaces generated by the pipeline, parcellations plotted on native surface, structural connectome matrices, functional connectome matrices, geodesic distance matrices, microstructural intensity profiles and connectomes and microstructural profiles (image intensities at each cortical depth) plotted on the native surface. Group level QC generates a color-coded table (with rows for subjects and columns for modules (FigurE 2B)).

\subsection{Additional features}

\section{Automatic bundle segmentation}

The micapipe repository also includes an optional automatic virtual dissection of major fiber tracts (Figure S2A). This tool is an adaptation of XTRACT (Warrington et al., 2020) implemented using Mrtrix 3 and ANTs, and its main purpose is to split a tractography (tck file) into the main white matter tracts. The automatic bundle segmentation uses already established automatic dissection protocols manually tuned for optimal performance. Derived from a full brain tractography, 35 bundles are virtually dissected using the LANIREM protocols. The quality of the full brain tractography will determine the quality of bundle separation. It is highly recommended to provide a tractography with more than one million streamlines, and QC for any errors. Strategies such as anatomically constrained tractography (ACT) and spherical deconvolution informed filtering of tractographies (SIFT), which are available in Mrtrix3, should aid in obtaining such high-quality tractographies. For processing a Nonlinear (SyN) registration of the native FA map to the FA atlas (FMRIB58_FA_1mm) is calculated. Resulting transformations are then applied to each bundle protocol to register them to the native FA space (DWI). Finally, each white matter bundle is filtered according to the dissection protocols.

\section{Anonymize function}

A function to anonymize the anatomical images from the BIDS directory for data sharing is provided within the micapipe repository as an extra feature. Native structural images are anonymized and deidentified with one of three different methods: de-facing, linear refacing or refacing with a non-linear warp field (Figure S2B). This tool uses a custom template and a set of ROIs specifically developed to identify the face and skull. The full head template was created using the T1-weighted images (resolution of $0.8 \times 0.8 \times 0.8 \mathrm{~mm}$ ) of 60 randomly selected healthy individuals from the MICA-MICs dataset (Royer et al., 2021). An inter-subject non-linear registration was performed without any mask, then the template was built using the mean of the normalized images. Three masks were generated: an ROI that covers the face, a brain mask, and a brain and neck mask. Unlike other algorithms, micapipe_anonymize supports different anatomical modalities (e.g., quantitative T1 maps).

\section{$\underline{4.4 \text { Feature matrices }}$}

Besides surfaces and parcellations, micapipe outputs up to four inter-regional matrices across several parcellation: structural connectome (SC), functional connectome (FC), geodesic distance (GD) and microstructural profile covariance (MPC). Rows and columns of GD and MPC matrices follow the 
order defined by annotation labels associated with their parcellation (see parcellations in the micapipe repository), including unique entries for the left and right medial walls. For example, row and column entries of the Schäfer-100 matrices are ordered according to: Left hemisphere cortical parcels (1 medial wall followed by 50 cortical regions), and right hemisphere cortical parcels ( 1 medial wall followed by 50 cortical regions). FC and SC matrices follow the same ordering, although entries for subcortical and cerebellar structures are appended before cortical parcels. As such, row and column entries of the Schäfer-100 FC and SC matrices are ordered according to: Subcortical structures and hippocampus (7 left, 7 right), cerebellar nodes ( 34 regions), left hemisphere cortical parcels (1 medial wall followed by 50 cortical regions), and right hemisphere cortical parcels ( 1 medial wall followed by 50 cortical regions). The ordering of all parcels and their corresponding label in each volumetric parcellation are documented in lookup tables provided in the micapipe repository (parcellations/lut). Further information about the organization and visualization of the output connectomes can be found in the respective section of the documentation.

\section{$\underline{4.5 \text { Validation experiments }}$}

The pipeline was tested in 455 human participants from seven datasets (TABLE S1, S4): MICA-MICs, (Royer et al., 2021), EpiC-UNAM (Rodríguez-Cruces et al., 2020), Cam-CAN (Shafto et al., 2014), SUDMEX (Angeles-Valdez et al., 2021), MSC (Gordon et al., 2017), and 7T-Audiopath (Sitek et al., 2019). EpiC-UNAM consists of two separate acquisitions: one cross-sectional and one longitudinal. Acquisition and processing details for each dataset can be found in the section "Processing databases" of the online documentation.

\section{Inter-subject consistency}

We assessed inter-subject consistency at the level of the first eigenvector/gradient of each matrix, matrix edges, and three widely graph theoretical measures (node strength, characteristic path length, clustering coefficient). Evaluations were carried out across three selected parcellations(Schäfer-100, 400 and 1000). Inter-subject consistency was quantified as the Spearman correlation between each participant measure and the group average measure for each available modality. This procedure was applied for the gradient 1, edges, and the three graph features (Figure 3).

To generate gradients, we used BrainSpace (http://brainspace.readthedocs.io, Vos de Wael et al., 2020), with the following options: normalized angle kernel, diffusion embedding with alpha $=0.5$ and automatic estimation of the diffusion time (See micapipe-supplementary for details). Group-level gradients were constructed from the average of subject-level cortical matrices. For MPC, FC, and GD, matrices were thresholded row-wise to retain the top $20 \%$ edges (see 'Building gradients' in the documentation, FigurE S3 for an example at the MICs dataset). SC matrices were log-transformed to reduce connectivity strength variance, but not thresholded. Moreover, left and right hemispheres were analyzed separately for SC, given limitations of diffusion tractography in mapping inter-hemispheric fibers. Hemispheres were also analyzed separately for GD gradients, as the surface-based measure of geodesic distance used here is computed on distinct hemisphere surface spheres. . The For each subject, we aligned the first gradient using Procrustes rotations to the group-level gradient for each modality, and computed correlations as a measure of inter-subject consistency.

Graph features: Graph measurements were computed using the igraph R package (igraph.org/r). We focused on three widely used graph-theoretical parameters, node strength, characteristic path length, and clustering coefficient (Rubinov and Sporns, 2010). We computed the clustering-coefficient as a measure of segregation, which provides information about the level of local connections in a network. 
The characteristic path length quantified network integration with short path lengths indicating globally efficient networks. Dijkstra's algorithm was used to calculate the inverse distance matrix (Dijkstra, 1959) and infinite path lengths were replaced with the maximum finite length (Van den Heuvel et al., 2008). Finally, we calculated strength to characterize the relevance of the individual nodes. FC strength was calculated only with positive values. Using the same thresholding as for the diffusion map embedding, GD, MPC and FC matrices were thresholded to retain the top $20 \%$ of the edges, and SC was analyzed using the un-thresholded, weighted networks.

\section{Inter-datasets similarity}

To assess stability across datasets, we computed Spearman's correlation coefficients between the grouplevel measures of each pair of datasets for each MRI modality (FIGURE 4).

\subsection{Version control and containers}

micapipe is executable via a Docker container, and we provide information on how to convert it to a singularity image either via directly pulling from $\underline{\text { dockerhub }}$ or converting a local image (Kurtzer et al., 2017). Each new version of micapipe is uploaded and tagged, and changes are documented. The current release version is v.0.1.2. Our goal is to maintain continuous integration. Additionally, our pipeline has adopted the standards of BIDS-Apps (Gorgolewski et al., 2017) and of the center for reproducible neuroimaging computation (Robert et al., 2016).

\section{ACKNOWLEDGEMENTS}

RRC received support from the Fonds de la Recherche du Québec - Santé (FRQ-S). JR received support from the Canadian Open Neuroscience Platform (CONP) and Canadian Institute of Health Research (CIHR). SL acknowledges funding from FRQ-S, CIHR, and the Richard and Ann Sievers Neuroscience Award. RVdW received support from the Savoy Foundation and the Richard and Ann Sievers Neuroscience Award. OB received support from the Healthy Brains for Healthy Lives (HBHL) program and the Transforming Autism Care Consortium (TACC). BP was supported by the National Research Foundation of Korea (NRF-2021R1F1A1052303), Institute for Information and Communications Technology Planning and Evaluation (IITP) funded by the Korea Government (MSIT) (2020-0-01389, Artificial Intelligence Convergence Research Center, Inha University; 2021-0-02068, Artificial Intelligence Innovation Hub), and Institute for Basic Science (IBS-R015-D1). LC acknowledges support from CONACYT (181508, 1782) and from UNAM-DGAPA (IB201712, IG200117, IN204720). BCB acknowledges support from CIHR (FDN-154298, PJT-174995), SickKids Foundation (NI17-039), Natural Sciences and Engineering Research Council (NSERC; Discovery-1304413), Azrieli Center for Autism Research of the Montreal Neurological Institute (ACAR), BrainCanada, FRQ-S, the Helmholtz International BigBrain Analytics and Learning Laboratory (Hiball), and the Canada Research Chairs Program (CRC). P.H. was supported in parts by funding from the Canada First Research Excellence Fund, awarded to McGill University for the Healthy Brains for Healthy Lives initiative, the National Institutes of Health (NIH) NIH-NIBIB P41 EB019936 (ReproNim), the National Institute Of Mental Health of the NIH under Award Number R01MH096906, a research scholar award from Brain Canada, in partnership with Health Canada, for the CONP initiative, as well as an Excellence Scholarship from Unifying Neuroscience and Artificial Intelligence - Québec. 


\section{REFERENCES}

Andersson JLR, Graham MS, Zsoldos E, Sotiropoulos SN. 2016. Incorporating outlier detection and replacement into a non-parametric framework for movement and distortion correction of diffusion MR images. Neuroimage 141:556-572. Doi:10.1016/j.neuroimage.2016.06.058

Andersson JLR, Skare S, Ashburner J. 2003. How to correct susceptibility distortions in spin-echo echo-planar images: application to diffusion tensor imaging. Neuroimage 20:870-888. Doi:10.1016/S10538119(03)00336-7

Andersson JLR, Sotiropoulos SN. 2016. An integrated approach to correction for off-resonance effects and subject movement in diffusion MR imaging. Neuroimage 125:1063-1078. Doi:10.1016/j.neuroimage.2015.10.019

Angeles-Valdez D, Rasgado-Toledo J, Issa-Garcia V, Balducci T, Villicaña V, Valencia A, Olvera JJG, ReyesZamorano E, Garza-Villarreal EA. 2021. SUDMEX CONN: The Mexican MRI dataset of patients with cocaine use disorder. Doi:10.1101/2021.09.03.21263048

Avants BB, Tustison NJ, Song G, Cook PA, Klein A, Gee JC. 2011. A reproducible evaluation of ANTs similarity metric performance in brain image registration. Neuroimage 54:2033-2044. Doi:10.1016/j.neuroimage.2010.09.025

Basser PJ, Mattiello J, LeBihan D. 1994. Estimation of the effective self-diffusion tensor from the NMR spin echo. J Magn Reson B 103:247-254. Doi:10.1006/jmrb.1994.1037

Bastiani M, Cottaar M, Fitzgibbon SP, Suri S, Alfaro-Almagro F, Sotiropoulos SN, Jbabdi S, Andersson JLR. 2019. Automated quality control for within and between studies diffusion MRI data using a non-parametric framework for movement and distortion correction. Neuroimage 184:801-812. Doi:10.1016/j.neuroimage.2018.09.073

Benkarim O, Paquola C, Park B-Y, Royer J, Rodríguez-Cruces R, de Wael RV, Misic B, Piella G, Bernhardt BC. 2021. A Riemannian approach to predicting brain function from the structural connectome. bioRxiv. Doi: 10.1101/2021.10.27.465906

Bernhardt BC, Fadaie F, Vos de Wael R, Hong S-J, Liu M, Guiot MC, Rudko DA, Bernasconi A, Bernasconi N. 2018. Preferential susceptibility of limbic cortices to microstructural damage in temporal lobe epilepsy: A quantitative T1 mapping study. Neuroimage 182:294-303. Doi:10.1016/j.neuroimage.2017.06.002

Betzel, R. F., \& Bassett, D. S. (2017). Multi-scale brain networks. Neuroimage, 160, $73-83$. doi:10.1016/j.neuroimage.2016.11.006

Betzel RF, Avena-Koenigsberger A, Goñi J, He Y, de Reus MA, Griffa A, Vértes PE, Mišic B, Thiran J-P, Hagmann P, van den Heuvel M, Zuo X-N, Bullmore ET, Sporns O. 2016. Generative models of the human connectome. NeuroImage. Doi:10.1016/j.neuroimage.2015.09.041

Betzel RF, Bassett DS. 2018. Specificity and robustness of long-distance connections in weighted, interareal connectomes. Proc Natl Acad Sci US A 115:E4880-E4889. Doi:10.1073/pnas.1720186115

Biswal BB, Mennes M, Zuo X-N, Gohel S, Kelly C, Smith SM, Beckmann CF, Adelstein JS, Buckner RL, Colcombe S, Dogonowski A-M, Ernst M, Fair D, Hampson M, Hoptman MJ, Hyde JS, Kiviniemi VJ, Kötter R, Li S-J, Lin C-P, Lowe MJ, Mackay C, Madden DJ, Madsen KH, Margulies DS, Mayberg HS, McMahon K, Monk CS, Mostofsky SH, Nagel BJ, Pekar JJ, Peltier SJ, Petersen SE, Riedl V, Rombouts SAR, Rypma B, Schlaggar BL, Schmidt S, Seidler RD, Siegle GJ, Sorg C, Teng G-J, Veijola J, Villringer A, Walter M, Wang L, Weng X-C, Whitfield-Gabrieli S, Williamson P, Windischberger C, Zang Y-F, Zhang H-Y, Xavier Castellanos F, Milham MP. 2010. Toward discovery science of human brain function. Proc Natl Acad Sci U $S$ A 107:4734-4739. Doi:10.1073/pnas.0911855107

Calamante F, Tournier J-D, Jackson GD, Connelly A. 2010. Track-density imaging (TDI): super-resolution white matter imaging using whole-brain track-density mapping. Neuroimage 53:1233-1243. Doi:10.1016/j.neuroimage.2010.07.024

Craddock C, Sharad S, Brian C, Ranjeet K, Satrajit G, Chaogan Y, Qingyang L, Daniel L, Joshua V, Randal B, Stanley C, Maarten M, Clare K, Adriana DM, Francisco C, Michael M. 2013. Towards Automated Analysis of Connectomes: The Configurable Pipeline for the Analysis of Connectomes (C-PAC). Frontiers in Neuroinformatics. Doi:10.3389/conf.fninf.2013.09.00042

Carey D, Caprini F, Allen M, Lutti A, Weiskopf N, Rees G, Callaghan MF, Dick F. 2018. Quantitative MRI provides markers of intra-, inter-regional, and age-related differences in young adult cortical microstructure. Neuroimage 182:429-440. Doi:10.1016/j.neuroimage.2017.11.066

Cieslak M, Cook PA, He X, Yeh F-C, Dhollander T, Adebimpe A, Aguirre GK, Bassett DS, Betzel RF, Bourque J, Cabral LM, Davatzikos C, Detre JA, Earl E, Elliott MA, Fadnavis S, Fair DA, Foran W, Fotiadis P, Garyfallidis E, Giesbrecht B, Gur RC, Gur RE, Kelz MB, Keshavan A, Larsen BS, Luna B, Mackey AP, Milham MP, Oathes DJ, Perrone A, Pines AR, Roalf DR, Richie-Halford A, Rokem A, Sydnor VJ, Tapera TM, Tooley UA, Vettel JM, Yeatman JD, Grafton ST, Satterthwaite TD. 2021. QSIPrep: an integrative platform for preprocessing and reconstructing diffusion MRI data. Nat Methods 18:775-778. Doi:10.1038/s41592-021-01185-5 
bioRxiv preprint doi: https://doi.org/10.1101/2022.01.31.478189; this version posted February $2,2022$. The copyright holder for this preprint (which was not certified by peer review) is the author/funder, who has granted bioRxiv a license to display the preprint in perpetuity. It is made available under aCC-BY 4.0 International license.

Coifman, Ronald R., and Stéphane Lafon. 2006. Diffusion maps. Appl Comput Harmon Anal 21:5-30. Doi:10.1016/j.acha.2006.04.006

Cooper, G., Finke, C., Chien, C., Brandt, A. U., Asseyer, S., Ruprecht, K., ... and Scheel, M. 2019. Standardization of T1w/T2w ratio improves detection of tissue damage in multiple sclerosis. Frontiers in neurology, 10, 334. Doi: 10.3389/fneur.2019.00334

Cordero-Grande L, Christiaens D, Hutter J, Price AN, Hajnal JV. 2019. Complex diffusion-weighted image estimation via matrix recovery under general noise models. Neuroimage 200:391-404. Doi:10.1016/j.neuroimage.2019.06.039

Cox RW. 1996. AFNI: software for analysis and visualization of functional magnetic resonance neuroimages. Comput Biomed Res 29:162-173. Doi:10.1006/cbmr.1996.0014

Craddock RC, Tungaraza RL, Milham MP. 2015. Connectomics and new approaches for analyzing human brain functional connectivity. Gigascience 4:13. Doi:10.1186/s13742-015-0045-X

Daducci A, Gerhard S, Griffa A, Lemkaddem A, Cammoun L, Gigandet X, Meuli R, Hagmann P, Thiran J-P. 2012. The connectome mapper: an open-source processing pipeline to map connectomes with MRI. PloS One 7:e48121. Doi:10.1371/journal.pone.0048121

Das SR, Avants BB, Grossman M, Gee JC. 2009. Registration based cortical thickness measurement. Neuroimage 45:867-879. Doi:10.1016/j.neuroimage.2008.12.016

Deoni, S. C., Dean III, D. C., O'Muircheartaigh, J., Dirks, H., \& Jerskey, B. A. 2012. Investigating white matter development in infancy and early childhood using myelin water faction and relaxation time mapping. Neuroimage, 63(3), 1038-1053. Doi:10.1016/j.neuroimage.2012.07.037

Desikan RS, Ségonne F, Fischl B, Quinn BT, Dickerson BC, Blacker D, Buckner RL, Dale AM, Maguire RP, Hyman BT, Albert MS, Killiany RJ. 2006. An automated labeling system for subdividing the human cerebral cortex on MRI scans into gyral based regions of interest. Neuroimage 31:968-980. Doi:10.1016/j.neuroimage.2006.01.021

Destrieux C, Fischl B, Dale A, Halgren E. 2010. Automatic parcellation of human cortical gyri and sulci using standard anatomical nomenclature. Neuroimage 53:1-15. Doi:10.1016/j.neuroimage.2010.06.010

Dhollander, T., Raffelt, D., \& Connelly, A. 2016 Unsupervised 3-tissue response function estimation from singleshell or multi-shell diffusion MR data without a co-registered T1 imageVol. 5, No. 5. Presented at the ISMRM Workshop on Breaking the Barriers of Diffusion MRI. ISMRM.

Diedrichsen J, Balsters JH, Flavell J, Cussans E, Ramnani N. 2009. A probabilistic MR atlas of the human cerebellum. Neuroimage 46:39-46. Doi:10.1016/j.neuroimage.2009.01.045

Dijkstra EW. 1959. A note on two problems in connexion with graphs. Numerische Mathematik. Doi: $10.1007 / \mathrm{bf} 01386390$

Du, G., Lewis, M. M., Sica, C., Kong, L., and Huang, X. 2019. Magnetic resonance T 1w/T 2w ratio: A parsimonious marker for Parkinson disease. Annals of neurology, 85(1), 96-104. doi:10.1002/ana.25376

Ecker C, Ronan L, Feng Y, Daly E, Murphy C, Ginestet CE, Brammer M, Fletcher PC, Bullmore ET, Suckling J, Baron-Cohen S, Williams S, Loth E, MRC AIMS Consortium, Murphy DGM. 2013. Intrinsic gray-matter connectivity of the brain in adults with autism spectrum disorder. Proc Natl Acad Sci U S A 110:1322213227. Doi:10.1073/pnas. 1221880110

Eickhoff SB, Yeo BTT, Genon S. 2018. Imaging-based parcellations of the human brain. Nat Rev Neurosci 19:672-686. Doi:10.1038/s41583-018-0071-7

Esteban O, Markiewicz CJ, Blair RW, Moodie CA, Isik AI, Erramuzpe A, Kent JD, Goncalves M, DuPre E, Snyder M, Oya H, Ghosh SS, Wright J, Durnez J, Poldrack RA, Gorgolewski KJ. 2019. fMRIPrep: a robust preprocessing pipeline for functional MRI. Nat Methods 16:111-116. Doi:10.1038/s41592-018-0235-4

Fan L, Li H, Zhuo J, Zhang Y, Wang J, Chen L, Yang Z, Chu C, Xie S, Laird AR, Fox PT, Eickhoff SB, Yu C, Jiang T. 2016. The Human Brainnetome Atlas: A New Brain Atlas Based on Connectional Architecture. Cerebral Cortex. Doi:10.1093/cercor/bhw157

Fischl B. 2012. FreeSurfer. NeuroImage. Doi:10.1016/j.neuroimage.2012.01.021

Fischl B, Sereno MI, Tootell RBH, Dale AM. 1999. High-resolution intersubject averaging and a coordinate system for the cortical surface. Human Brain Mapping. Doi:10.1002/(sici)1097-0193(1999)8:4<272::aidhbm10>3.0.co;2-4

Genon S, Bernhardt BC, La Joie R, Amunts K, Eickhoff SB. 2021. The many dimensions of human hippocampal organization and (dys)function. Trends Neurosci 44:977-989. Doi:10.1016/j.tins.2021.10.003

Genon S, Reid A, Langner R, Amunts K, Eickhoff SB. 2018. How to Characterize the Function of a Brain Region. Trends Cogn Sci 22:350-364. Doi:10.1016/j.tics.2018.01.010

Glasser MF, Coalson TS, Robinson EC, Hacker CD, Harwell J, Yacoub E, Ugurbil K, Andersson J, Beckmann CF, Jenkinson M, Smith SM, Van Essen DC. 2016. A multi-modal parcellation of human cerebral cortex. Nature 536:171-178. Doi:10.1038/nature18933

Glasser MF, Van Essen DC. 2011. Mapping human cortical areas in vivo based on myelin content as revealed by 
bioRxiv preprint doi: https://doi.org/10.1101/2022.01.31.478189; this version posted February 2, 2022. The copyright holder for this preprint (which was not certified by peer review) is the author/funder, who has granted bioRxiv a license to display the preprint in perpetuity. It is made available under aCC-BY 4.0 International license.

T1- and T2-weighted MRI. J Neurosci 31:11597-11616. Doi:10.1523/JNEUROSCI.2180-11.2011

Gordon EM, Laumann TO, Gilmore AW, Newbold DJ, Greene DJ, Berg JJ, Ortega M, Hoyt-Drazen C, Gratton C, Sun H, Hampton JM, Coalson RS, Nguyen AL, McDermott KB, Shimony JS, Snyder AZ, Schlaggar BL, Petersen SE, Nelson SM, Dosenbach NUF. 2017. Precision Functional Mapping of Individual Human Brains. Neuron 95:791-807.e7. doi:10.1016/j.neuron.2017.07.011

Gorgolewski KJ, Alfaro-Almagro F, Auer T, Bellec P, Capotă M, Chakravarty MM, Churchill NW, Cohen AL, Craddock RC, Devenyi GA, Eklund A, Esteban O, Flandin G, Ghosh SS, Guntupalli JS, Jenkinson M, Keshavan A, Kiar G, Liem F, Raamana PR, Raffelt D, Steele CJ, Quirion P-O, Smith RE, Strother SC, Varoquaux G, Wang Y, Yarkoni T, Poldrack RA. 2017. BIDS apps: Improving ease of use, accessibility, and reproducibility of neuroimaging data analysis methods. PloS Comput Biol 13:e1005209. Doi:10.1371/journal.pcbi.1005209

Gorgolewski, Krzysztof J., Tibor Auer, Vince D. Calhoun, R. Cameron Craddock, Samir Das, Eugene P. Duff, Guillaume Flandin, et al. 2016. "The Brain Imaging Data Structure, a Format for Organizing and Describing Outputs of Neuroimaging Experiments.” Scientific Data 3 (June): 160044.

Granberg T, Fan Q, Treaba CA, Ouellette R, Herranz E, Mangeat G, Louapre C, Cohen-Adad J, Klawiter EC, Sloane JA, Mainero C. 2017. In vivo characterization of cortical and white matter neuroaxonal pathology in early multiple sclerosis. Brain 140:2912-2926. Doi:10.1093/brain/awx247

Greve DN, Fischl B. 2009. Accurate and robust brain image alignment using boundary-based registration. Neuroimage 48:63-72. Doi:10.1016/j.neuroimage.2009.06.060

Griffanti L, Salimi-Khorshidi G, Beckmann CF, Auerbach EJ, Douaud G, Sexton CE, Zsoldos E, Ebmeier KP, Filippini N, Mackay CE, Moeller S, Xu J, Yacoub E, Baselli G, Ugurbil K, Miller KL, Smith SM. 2014. ICA-based artefact removal and accelerated fMRI acquisition for improved resting state network imaging. Neuroimage 95:232-247. Doi:10.1016/j.neuroimage.2014.03.034

Halchenko Y, Meyer K, Poldrack B, Solanky D, Wagner A, Gors J, MacFarlane D, Pustina D, Sochat V, Ghosh S, Mönch C, Markiewicz C, Waite L, Shlyakhter I, de la Vega A, Hayashi S, Häusler C, Poline J-B, Kadelka T, Skytén K, Jarecka D, Kennedy D, Strauss T, Cieslak M, Vavra P, Ioanas H-I, Schneider R, Pflüger M, Haxby J, Eickhoff S, Hanke M. 2021. DataLad: distributed system for joint management of code, data, and their relationship. Journal of Open Source Software. Doi:10.21105/joss.03262

Hong S-J, Valk SL, Di Martino A, Milham MP, Bernhardt BC. 2018. Multidimensional Neuroanatomical Subtyping of Autism Spectrum Disorder. Cereb Cortex 28:3578-3588. Doi:10.1093/cercor/bhx229

Hong, S. J., Hyung, B., Paquola, C., \& Bernhardt, B. C. (2019). The superficial white matter in autism and its role in connectivity anomalies and symptom severity. Cerebral Cortex, 29(10), 4415-4425. doi:10.1093/cercor/bhy321

Huntenburg JM, Bazin P-L, Margulies DS. 2018. Large-Scale Gradients in Human Cortical Organization. Trends Cogn Sci 22:21-31. Doi:10.1016/j.tics.2017.11.002

Huntenburg JM, Yeow LY, Mandino F, Grandjean J. 2021. Gradients of functional connectivity in the mouse cortex reflect neocortical evolution. Neuroimage 225:117528. Doi:10.1016/j.neuroimage.2020.117528

Jbabdi S, Woolrich MW, Andersson JLR, Behrens TEJ. 2007. A Bayesian framework for global tractography. Neuroimage 37:116-129. Doi:10.1016/j.neuroimage.2007.04.039

Jenkinson M, Beckmann CF, Behrens TEJ, Woolrich MW, Smith SM. 2012. FSL. NeuroImage. Doi:10.1016/j.neuroimage.2011.09.015

Jeurissen B, Tournier J-D, Dhollander T, Connelly A, Sijbers J. 2014. Multi-tissue constrained spherical deconvolution for improved analysis of multi-shell diffusion MRI data. Neuroimage 103:411-426. Doi:10.1016/j.neuroimage.2014.07.061

Kellner E, Dhital B, Kiselev VG, Reisert M. 2016. Gibbs-ringing artifact removal based on local subvoxel-shifts. Magn Reson Med 76:1574-1581. Doi:10.1002/mrm.26054

Kim JS, Singh V, Lee JK, Lerch J, Ad-Dab'bagh Y, MacDonald D, Lee JM, Kim SI, Evans AC. 2005. Automated 3-D extraction and evaluation of the inner and outer cortical surfaces using a Laplacian map and partial volume effect classification. Neuroimage 27:210-221. Doi:10.1016/j.neuroimage.2005.03.036

Kurtzer GM, Sochat V, Bauer MW. 2017. Singularity: Scientific containers for mobility of compute. PloS One 12:e0177459. Doi:10.1371/journal.pone.0177459

Larivière S, Vos de Wael R, Paquola C, Hong S-J, Mišić B, Bernasconi N, Bernasconi A, Bonilha L, Bernhardt BC. 2019. Microstructure-Informed Connectomics: Enriching Large-Scale Descriptions of Healthy and Diseased Brains. Brain Connect 9:113-127. Doi:10.1089/brain.2018.0587

Lebel, C., \& Deoni, S. 2018. The development of brain white matter microstructure. Neuroimage, 182, 207-218. Doi:10.1016/j.neuroimage.2017.12.097

Liu, M., Bernhardt, B. C., Hong, S. J., Caldairou, B., Bernasconi, A., \& Bernasconi, N. (2016). The superficial white matter in temporal lobe epilepsy: a key link between structural and functional network disruptions. Brain, 139(9), 2431-2440. doi:10.1093/brain/aww167 
bioRxiv preprint doi: https://doi.org/10.1101/2022.01.31.478189; this version posted February 2, 2022. The copyright holder for this preprint (which was not certified by peer review) is the author/funder, who has granted bioRxiv a license to display the preprint in perpetuity. It is made available under aCC-BY 4.0 International license.

Marcus DS, Harwell J, Olsen T, Hodge M, Glasser MF, Prior F, Jenkinson M, Laumann T, Curtiss SW, Van Essen DC. 2011. Informatics and data mining tools and strategies for the human connectome project. Front Neuroinform 5:4. Doi:10.3389/fninf.2011.00004

Margulies DS, Ghosh SS, Goulas A, Falkiewicz M, Huntenburg JM, Langs G, Bezgin G, Eickhoff SB, Castellanos FX, Petrides M, Jefferies E, Smallwood J. 2016. Situating the default-mode network along a principal gradient of macroscale cortical organization. Proc Natl Acad Sci U S A 113:12574-12579. Doi:10.1073/pnas.1608282113

Mars RB, Jbabdi S, Rushworth MFS. 2021. A Common Space Approach to Comparative Neuroscience. Annu Rev Neurosci 44:69-86. Doi:10.1146/annurev-neuro-100220-025942

Milham MP, Craddock RC, Son JJ, Fleischmann M, Clucas J, Xu H, Koo B, Krishnakumar A, Biswal BB, Castellanos FX, Colcombe S, Di Martino A, Zuo X-N, Klein A. 2018. Assessment of the impact of shared brain imaging data on the scientific literature. Nat Commun 9:2818. Doi:10.1038/s41467-018-04976-1

Müller EJ, Munn B, Hearne LJ, Smith JB, Fulcher B, Arnatkevičiūtė A, Lurie DJ, Cocchi L, Shine JM. 2020. Core and matrix thalamic sub-populations relate to spatio-temporal cortical connectivity gradients. Neuroimage 222:117224. Doi:10.1016/j.neuroimage.2020.117224

Murphy, Kevin, Rasmus M. Birn, Daniel A. Handwerker, Tyler B. Jones, and Peter A. Bandettini. 2009. "The Impact of Global Signal Regression on Resting State Correlations: Are Anti-Correlated Networks Introduced?” NeuroImage 44 (3): 893-905. Doi:10.1016/j.neuroimage.2008.09.036

Murphy, Kevin, and Michael D. Fox. 2017. “Towards a Consensus Regarding Global Signal Regression for Resting State Functional Connectivity MRI.” NeuroImage 154 (July): 169-73.

Doi:10.1016/j.neuroimage.2016.11.052

Paquola C, Bethlehem RAI, Seidlitz J, Wagstyl K, Romero-Garcia R, Whitaker KJ, De Wael RV, Williams GB, Vértes PE, Margulies DS, Bernhardt BC, Bullmore ET, NSPN Consortium. N.d. A moment of change: shifts in myeloarchitecture characterise adolescent development of cortical gradients. Doi:10.1101/706341

Paquola C, Bethlehem RA, Seidlitz J, Wagstyl K, Romero-Garcia R, Whitaker KJ, Vos de Wael R, Williams GB, NSPN Consortium, Vértes PE, Margulies DS, Bernhardt B, Bullmore ET. 2019a. Shifts in myeloarchitecture characterise adolescent development of cortical gradients. Elife 8. Doi:10.7554/eLife.50482

Paquola C, Royer J, Lewis LB, Lepage C, Glatard T, Wagstyl K, DeKraker J, Toussaint P-J, Valk SL, Collins L, Khan AR, Amunts K, Evans AC, Dickscheid T, Bernhardt B. 2021. The BigBrainWarp toolbox for integration of BigBrain 3D histology with multimodal neuroimaging. Elife 10. Doi:10.7554/eLife.70119

Paquola C, Seidlitz J, Benkarim O, Royer J, Klimes P, Bethlehem RAI, Larivière S, Vos de Wael R, RodríguezCruces R, Hall JA, Frauscher B, Smallwood J, Bernhardt BC. 2020. A multi-scale cortical wiring space links cellular architecture and functional dynamics in the human brain. PloS Biol 18:e3000979. Doi:10.1371/journal.pbio.3000979

Paquola C, Vos De Wael R, Wagstyl K, Bethlehem RAI, Hong S-J, Seidlitz J, Bullmore ET, Evans AC, Misic B, Margulies DS, Smallwood J, Bernhardt BC. 2019b. Microstructural and functional gradients are increasingly dissociated in transmodal cortices. PloS Biol 17:e3000284. Doi:10.1371/journal.pbio.3000284

Patenaude B, Smith SM, Kennedy DN, Jenkinson M. 2011. A Bayesian model of shape and appearance for subcortical brain segmentation. Neuroimage 56:907-922. Doi:10.1016/j.neuroimage.2011.02.046

Raffelt, David and Dhollander, Thijs and Tournier, J-Donald and Tabbara, Rami and Smith, Robert E and Pierre, Eric and Connelly, Alan. 2017. Bias field correction and intensity normalisation for quantitative analysis of apparent fibre density. Proc Intl Soc Mag Reson Med 25:3541.

Robert B, Satrajit G, Jeffrey G, Yaroslav H, Christian H, David K, David K, Maryann M, Jean-Baptiste P, Nina P, Matt T. 2016. ReproNim: A Center for Reproducible Neuroimaging Computation to support Resource Discovery, Interoperability, and Replicable Results. Frontiers in Neuroinformatics. Doi:10.3389/conf.fninf.2016.20.00083

Rodríguez-Cruces R, Bernhardt BC, Concha L. 2020. Multidimensional associations between cognition and connectome organization in temporal lobe epilepsy. Neuroimage 213:116706. Doi:10.1016/j.neuroimage.2020.116706

Royer J, Paquola C, Larivière S, Vos de Wael R, Tavakol S, Lowe AJ, Benkarim O, Evans AC, Bzdok D, Smallwood J, Frauscher B, Bernhardt BC. 2020. Myeloarchitecture gradients in the human insula: Histological underpinnings and association to intrinsic functional connectivity. Neuroimage 216:116859. Doi:10.1016/j.neuroimage.2020.116859

Royer J, Rodríguez-Cruces R, Tavakol S, Larivière S, Herholz P, Li Q, de Wael RV, Paquola C, Benkarim O, Park B-Y, Lowe AJ, Margulies D, Smallwood J, Bernasconi A, Bernasconi N, Frauscher B, Bernhardt BC. N.d. An Open MRI Dataset for Multiscale Neuroscience. doi:10.1101/2021.08.04.454795

Rubinov M, Sporns O. 2010. Complex network measures of brain connectivity: uses and interpretations. Neuroimage 52:1059-1069. Doi:10.1016/j.neuroimage.2009.10.003

Salimi-Khorshidi G, Douaud G, Beckmann CF, Glasser MF, Griffanti L, Smith SM. 2014. Automatic denoising of functional MRI data: combining independent component analysis and hierarchical fusion of classifiers. 
bioRxiv preprint doi: https://doi.org/10.1101/2022.01.31.478189; this version posted February $2,2022$. The copyright holder for this preprint (which was not certified by peer review) is the author/funder, who has granted bioRxiv a license to display the preprint in perpetuity. It is made available under aCC-BY 4.0 International license.

Neuroimage 90:449-468. Doi:10.1016/j.neuroimage.2013.11.046

Schäfer A, Kong R, Gordon EM, Laumann TO, Zuo X-N, Holmes AJ, Eickhoff SB, Thomas Yeo BT. 2018. Local-Global Parcellation of the Human Cerebral Cortex from Intrinsic Functional Connectivity MRI. Cerebral Cortex. Doi:10.1093/cercor/bhx179

Scholtens LH, de Reus MA, de Lange SC, Schmidt R, van den Heuvel MP. 2018. An MRI Von Economo Koskinas atlas. Neuroimage 170:249-256. Doi:10.1016/j.neuroimage.2016.12.069

Shafto MA, Tyler LK, Dixon M, Taylor JR, Rowe JB, Cusack R, Calder AJ, Marslen-Wilson WD, Duncan J, Dalgleish T, Henson RN, Brayne C, Matthews FE, Cam-CAN. 2014. The Cambridge Centre for Ageing and Neuroscience (Cam-CAN) study protocol: a cross-sectional, lifespan, multidisciplinary examination of healthy cognitive ageing. BMC Neurol 14:204. Doi:10.1186/s12883-014-0204-1

Sitek KR, Gulban OF, Calabrese E, Johnson GA, Lage-Castellanos A, Moerel M, Ghosh SS, De Martino F. 2019. Mapping the human subcortical auditory system using histology, postmortem MRI and in vivo MRI at 7T. Elife 8. Doi:10.7554/eLife.48932

Smallwood, J., Bernhardt, B. C., Leech, R., Bzdok, D., Jefferies, E., \& Margulies, D. S. 2021. The default mode network in cognition: a topographical perspective. Nature reviews neuroscience, 22(8), 503-513.

Doi:10.1038/s41583-021-00474-4

Smith RE, Tournier J-D, Calamante F, Connelly A. 2015a. SIFT2: Enabling dense quantitative assessment of brain white matter connectivity using streamlines tractography. Neuroimage 119:338-351. Doi:10.1016/j.neuroimage.2015.06.092

Smith RE, Tournier J-D, Calamante F, Connelly A. 2015b. The effects of SIFT on the reproducibility and biological accuracy of the structural connectome. Neuroimage 104:253-265. Doi:10.1016/j.neuroimage.2014.10.004

Smith RE, Tournier J-D, Calamante F, Connelly A. 2012. Anatomically-constrained tractography: Improved diffusion MRI streamlines tractography through effective use of anatomical information. NeuroImage. Doi:10.1016/j.neuroimage.2012.06.005

Smith SM, Jenkinson M, Woolrich MW, Beckmann CF, Behrens TEJ, Johansen-Berg H, Bannister PR, De Luca M, Drobnjak I, Flitney DE, Niazy RK, Saunders J, Vickers J, Zhang Y, De Stefano N, Brady JM, Matthews PM. 2004. Advances in functional and structural MR image analysis and implementation as FSL. Neuroimage 23 Suppl 1:S208-19. Doi:10.1016/j.neuroimage.2004.07.051

Suárez LE, Markello RD, Betzel RF, Misic B. 2020. Linking Structure and Function in Macroscale Brain Networks. Trends in Cognitive Sciences. Doi:10.1016/j.tics.2020.01.008

Tian Y, Margulies DS, Breakspear M, Zalesky A. 2020. Topographic organization of the human subcortex unveiled with functional connectivity gradients. Nat Neurosci 23:1421-1432. Doi:10.1038/s41593-02000711-6

Tierney A, Dick F, Deutsch D, Sereno M. 2013. Speech versus song: multiple pitch-sensitive areas revealed by a naturally occurring musical illusion. Cereb Cortex 23:249-254. Doi:10.1093/cercor/bhs003

Tournier J-D, Calamante F, Connelly A. 2012. Mrtrix: Diffusion tractography in crossing fiber regions. International Journal of Imaging Systems and Technology. Doi:10.1002/ima.22005

Tournier J-D, Calamante F, Gadian DG, Connelly A. 2004. Direct estimation of the fiber orientation density function from diffusion-weighted MRI data using spherical deconvolution. Neuroimage 23:1176-1185. Doi:10.1016/j.neuroimage.2004.07.037

Tournier, J Donald and Calamante, Fernando and Connelly, Alan and others. 2010. Improved probabilistic streamlines tractography by 2 nd order integration over fibre orientation distributions. Proc Int Soc Magn Reson Med Sci Meet Exhib Int Soc Magn Reson Med Sci Meet Exhib 1670.

Tournier J-D, Smith R, Raffelt D, Tabbara R, Dhollander T, Pietsch M, Christiaens D, Jeurissen B, Yeh C-H, Connelly A. 2019. Mrtrix3: A fast, flexible and open software framework for medical image processing and visualisation. Neuroimage 202:116137. Doi:10.1016/j.neuroimage.2019.116137

Turner, R. 2019. Myelin and modeling: Bootstrapping cortical microcircuits. Frontiers in neural circuits, $13,34$. Doi:10.3389/fncir.2019.00034

Tustison NJ, Avants BB. 2013. Explicit B-spline regularization in diffeomorphic image registration. Front Neuroinform 7:39. Doi:10.3389/fninf.2013.00039

Tustison NJ, Avants BB, Cook PA, Gee JC. 2010. N4ITK: Improved N3 bias correction with robust B-spline approximation. 2010 IEEE International Symposium on Biomedical Imaging: From Nano to Macro. Doi:10.1109/isbi.2010.5490078

Valk SL, Xu T, Margulies DS, Masouleh SK, Paquola C, Goulas A, Kochunov P, Smallwood J, Yeo BTT, Bernhardt BC, Eickhoff SB. 2020. Shaping brain structure: Genetic and phylogenetic axes of macroscale organization of cortical thickness. Sci Adv 6. Doi:10.1126/sciadv.abb3417

Van den Heuvel MP, Scholtens LH, Kahn RS. 2019. Multiscale Neuroscience of Psychiatric Disorders. Biological Psychiatry. Doi:10.1016/j.biopsych.2019.05.015 
Van den Heuvel MP, Thomas Yeo BT. 2017. A Spotlight on Bridging Microscale and Macroscale Human Brain Architecture. Neuron. Doi:10.1016/j.neuron.2017.02.048

Van den Heuvel MP, Stam CJ, Boersma M, Hulshoff Pol HE. 2008. Small-world and scale-free organization of voxel-based resting-state functional connectivity in the human brain. Neuroimage 43:528-539. doi:10.1016/j.neuroimage.2008.08.010

Van Essen DC, Glasser MF, Dierker DL, Harwell J, Coalson T. 2012. Parcellations and hemispheric asymmetries of human cerebral cortex analyzed on surface-based atlases. Cereb Cortex 22:2241-2262. Doi:10.1093/cercor/bhr291

Van Essen DC, Smith SM, Barch DM, Behrens TEJ, Yacoub E, Ugurbil K, WU-Minn HCP Consortium. 2013. The WU-Minn Human Connectome Project: an overview. Neuroimage 80:62-79. Doi:10.1016/j.neuroimage.2013.05.041

Van Essen DC, Ugurbil K, Auerbach E, Barch D, Behrens TEJ, Bucholz R, Chang A, Chen L, Corbetta M, Curtiss SW, Della Penna S, Feinberg D, Glasser MF, Harel N, Heath AC, Larson-Prior L, Marcus D, Michalareas G, Moeller S, Oostenveld R, Petersen SE, Prior F, Schlaggar BL, Smith SM, Snyder AZ, Xu J, Yacoub E, WU-Minn HCP Consortium. 2012. The Human Connectome Project: a data acquisition perspective. Neuroimage 62:2222-2231. Doi:10.1016/j.neuroimage.2012.02.018

Vázquez-Rodríguez B, Suárez LE, Markello RD, Shafiei G, Paquola C, Hagmann P, van den Heuvel MP, Bernhardt BC, Spreng RN, Misic B. 2019. Gradients of structure-function tethering across neocortex. Proc Natl Acad Sci U S A 116:21219-21227. Doi:10.1073/pnas.1903403116

Veraart J, Novikov DS, Christiaens D, Ades-Aron B, Sijbers J, Fieremans E. 2016. Denoising of diffusion MRI using random matrix theory. Neuroimage 142:394-406. Doi:10.1016/j.neuroimage.2016.08.016

Veraart J, Sijbers J, Sunaert S, Leemans A, Jeurissen B. 2013. Weighted linear least squares estimation of diffusion MRI parameters: strengths, limitations, and pitfalls. Neuroimage 81:335-346. Doi:10.1016/j.neuroimage.2013.05.028

Von Economo C. 2009. Cellular Structure of the Human Cerebral Cortex. Karger Medical and Scientific Publishers.

Vos de Wael R, Benkarim O, Paquola C, Lariviere S, Royer J, Tavakol S, Xu T, Hong S-J, Langs G, Valk S, Misic B, Milham M, Margulies D, Smallwood J, Bernhardt BC. 2020. BrainSpace: a toolbox for the analysis of macroscale gradients in neuroimaging and connectomics datasets. Commun Biol 3:103. Doi:10.1038/s42003-020-0794-7

Vos de Wael R, Royer J, Tavakol S, Wang Y, Paquola C, Benkarim O, Eichert N, Larivière S, Xu T, Misic B, Smallwood J, Valk SL, Bernhardt BC. 2021. Structural Connectivity Gradients of the Temporal Lobe Serve as Multiscale Axes of Brain Organization and Cortical Evolution. Cereb Cortex 31:5151-5164. Doi:10.1093/cercor/bhab149

Vos de Wael R, Larivière S, Caldairou B, Hong S-J, Margulies DS, Jefferies E, Bernasconi A, Smallwood J, Bernasconi N, Bernhardt BC. 2018. Anatomical and microstructural determinants of hippocampal subfield functional connectome embedding. Proceedings of the National Academy of Sciences. Doi:10.1073/pnas.1803667115

Vos de Wael R, Hyder F, Thompson GJ. 2017. Effects of Tissue-Specific Functional Magnetic Resonance Imaging Signal Regression on Resting-State Functional Connectivity. Brain Connect 7:482-490. doi:10.1089/brain.2016.0465

Waehnert, M. D., Dinse, J., Schäfer, A., Geyer, S., Bazin, P. L., Turner, R., \& Tardif, C. L. 2016. A subjectspecific framework for in vivo myeloarchitectonic analysis using high resolution quantitative MRI. Neuroimage, 125, 94-107. doi: 10.1016/j.neuroimage.2015.10.001

Waehnert, M. D., Dinse, J., Weiss, M., Streicher, M. N., Waehnert, P., Geyer, S., Turner R and Bazin, P. L. (2014). Anatomically motivated modeling of cortical laminae. Neuroimage, 93, 210-220. doi:10.1016/j.neuroimage.2013.03.078

Wang Y, Royer J, Park B-Y, de Wael RV, Larivière S, Tavakol S, Rodriguez-Cruces R, Paquola C, Hong S-J, Margulies DS, Smallwood J, Valk SL, Evans AC, Bernhardt BC. 2021. Long-range connections mirror and link microarchitectural and cognitive hierarchies in the human brain. bioRxiv. Doi:10.1101/2021.10.25.465692

Warrington S, Bryant KL, Khrapitchev AA, Sallet J, Charquero-Ballester M, Douaud G, Jbabdi S, Mars RB, Sotiropoulos SN. XTRACT -- Standardised protocols for automated tractography in the human and macaque brain. 2020. Neuroimage 217:116923. Doi:10.1016/j.neuroimage.2020.116923

Whitfield-Gabrieli S, Nieto-Castanon A. 2012. Conn: a functional connectivity toolbox for correlated and anticorrelated brain networks. Brain Connect 2:125-141. Doi:10.1089/brain.2012.0073

Whitaker, K. J., Vértes, P. E., Romero-Garcia, R., Váša, F., Moutoussis, M., Prabhu, G., ... \& NSPN Consortium. (2016). Adolescence is associated with genomically patterned consolidation of the hubs of the human brain 
bioRxiv preprint doi: https://doi.org/10.1101/2022.01.31.478189; this version posted February 2, 2022. The copyright holder for this preprint (which was not certified by peer review) is the author/funder, who has granted bioRxiv a license to display the preprint in perpetuity. It is made available under aCC-BY 4.0 International license.

connectome. Proceedings of the National Academy of Sciences, 113(32), 9105-9110. Doi:10.1073/pnas.1601745113

Zhang Y, Brady M, Smith S. 2001. Segmentation of brain MR images through a hidden Markov random field model and the expectation-maximization algorithm. IEEE Trans Med Imaging 20:45-57. Doi:10.1109/42.906424 


\section{SUPPLEMENTARY FIGURES AND TABLES}

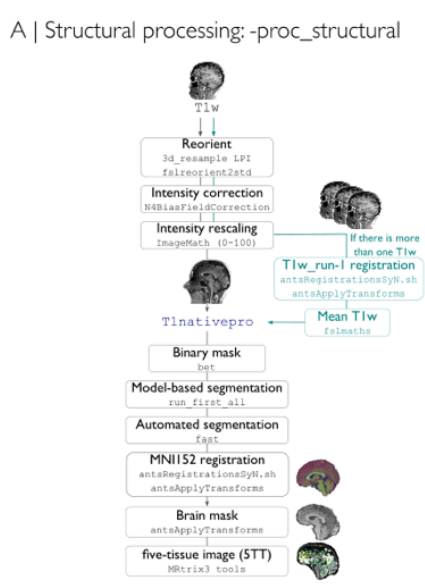

B | Post structural processing: -post_structural

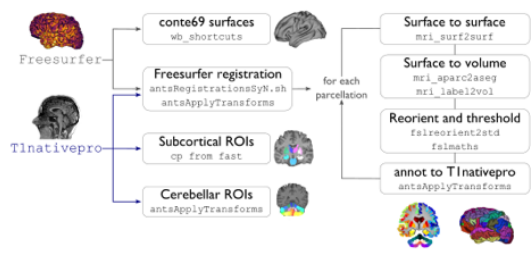

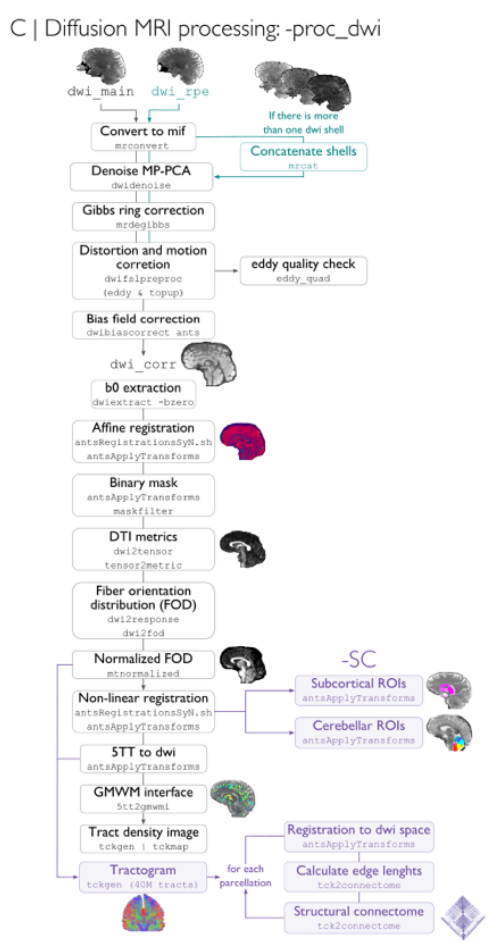

D | Functional MRI processing: -proc_rsfmri

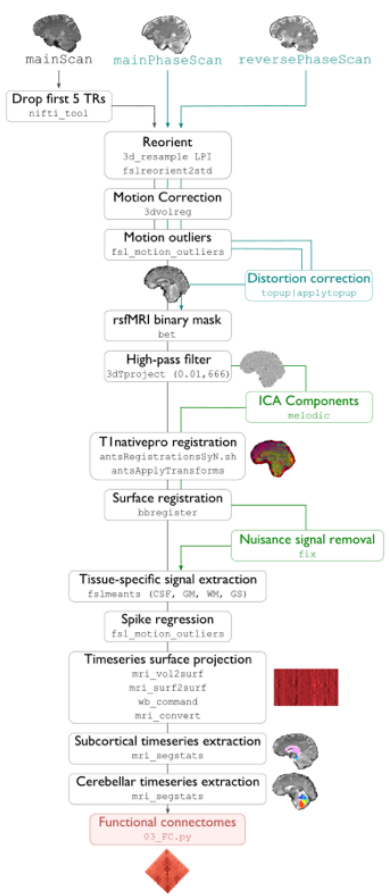

Figure S1. Core Processing Modules. A) The -proc structural module inputs a T1-weighted image, and generates a native space processed image (nativepro). This image will be used for registration purposes in all following steps. B) After FreeSurfer is run and T1nativepro is generated, the -post structural module registers native FreeSurfer surfaces to a standard template, in addition to mapping all cortical parcellation schemes to the subject's native surface space and nativepro space. C) The = proc dwi processes the native DWI data, and estimates a structural connectome (via $\underline{-\mathrm{SC}}$ ). We apply iFOD2 for this purpose, a probabilistic tractography algorithm. D) The -proc_rsfmri module performs all pre-processing of the rs-fMRI scans, in preparation for the construction of functional connectomes. 
bioRxiv preprint doi: https://doi. org/10.1101/2022 01.31.478189. this version posted February 2, 2022. The copyright holder for this preprint (which was not certified by peer review) is the author/funder, who has granted bioRxiv a license to display the preprint in perpetuity. It is made available under aCC-BY 4.0 International license.

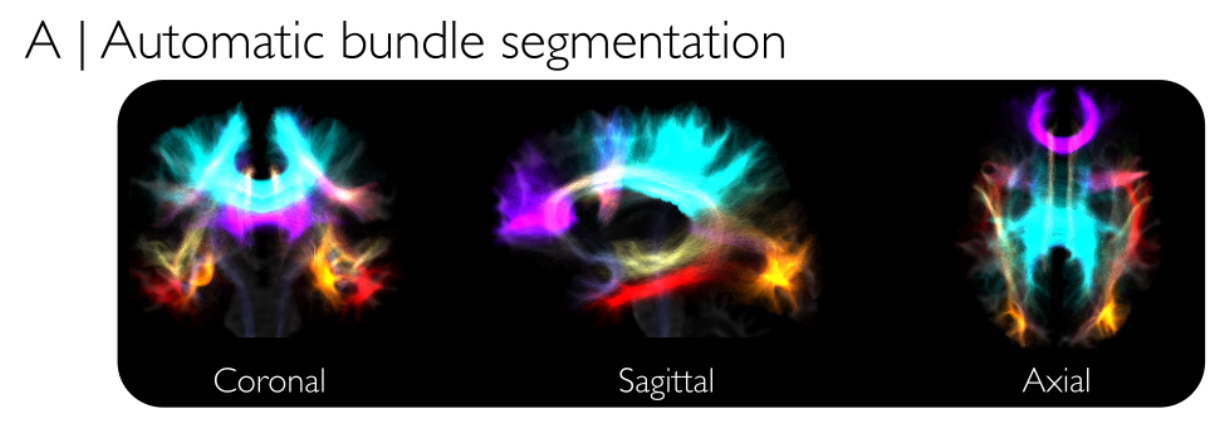

\section{$\mathrm{B} \mid$ Anonymize function}

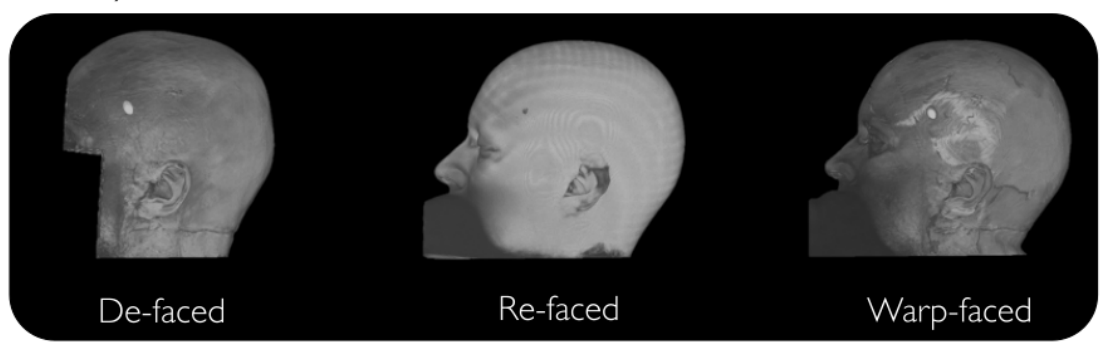

Figure S2. Additional features. A. Automatic bundle segmentation generating 35 virtually dissected white matter bundles. Segmented tracts obtained from whole-brain tractography generated in the -SC module. B. Anonymizing function for the anatomical images from the BIDS directory. Three different methods are available for defacing/refacing. 


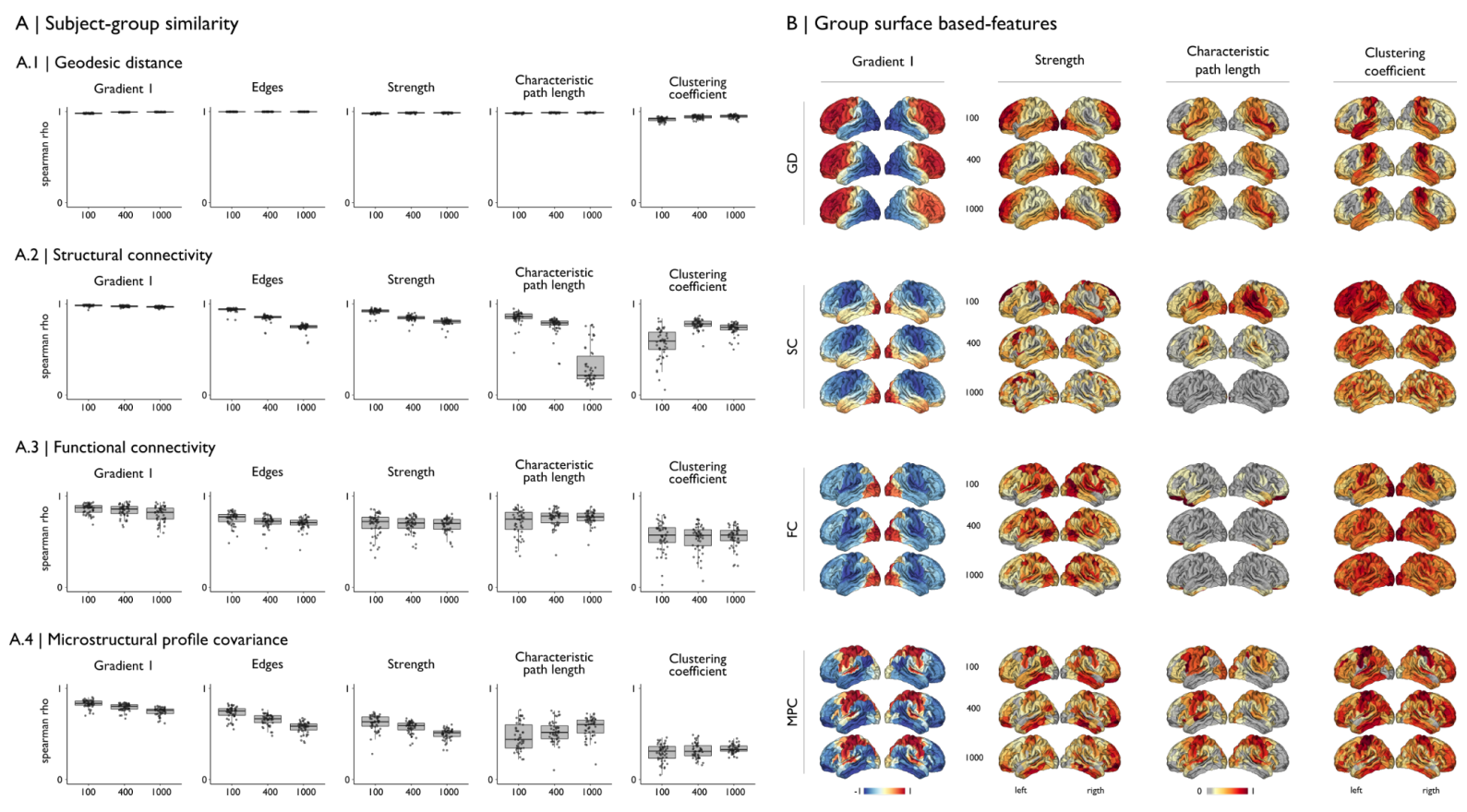

Figure S3. Within-dataset CONSiSTEnCY. A) Subject-group consistency for each modality and measurement in the MICs dataset. Each point in the boxplots corresponds to a Spearman's rho between each subject and the group average measurement, derived from the Schäfer-100,-400 and 1000 parcellations. B) Group average feature maps from the MICs dataset. 


\begin{tabular}{|c|c|c|c|c|c|c|c|c|}
\hline Database & Field & $\begin{array}{l}\text { Subjects } \\
\text { /sessions }\end{array}$ & $\mathrm{T} 1 \mathrm{w}$ & $\begin{array}{l}\text { DWI } \\
\text { main }\end{array}$ & $\begin{array}{l}\text { DWI } \\
\text { rpe }\end{array}$ & rs-fMRI & $\begin{array}{l}\text { rs-fMRI } \\
\text { rpe }\end{array}$ & $\begin{array}{l}\text { Quantitative } \\
\text { Image }\end{array}$ \\
\hline CamCan & $\begin{array}{c}\text { 3T } \\
\text { Siemens } \\
\text { TIM Trio }\end{array}$ & $130 / 1$ & $\begin{array}{c}1 \mathrm{~mm}^{3} \text { isotropic, } \\
\mathrm{FOV}=192 \times 256 \times 256\end{array}$ & $\begin{array}{c}2 \mathrm{~mm}^{3} \text { isotropic, } \\
\text { FOV }=96 \times 69 \times 66,30- \\
\text { b1000, and } 30-\mathrm{b} 2000 \text {, } \\
3-\mathrm{b} 0\end{array}$ & & $\begin{array}{c}3 \times 3 \times 4.44 \mathrm{~mm}^{3}, \\
\mathrm{FOV}=64 \times 64 \times 32 \times 246 \\
\mathrm{TE}=0.03, \mathrm{TR}=1.97\end{array}$ & & $\begin{array}{c}\text { MTR: } 1.6 \mathrm{~mm}^{3} \\
\text { isotropic, } \\
\text { FOV }=104 \times 128 \times 12 \\
8\end{array}$ \\
\hline$S U D M E X$ & $\begin{array}{l}\text { 3T Philips } \\
\text { Ingenia }\end{array}$ & $145 / 1$ & $\begin{array}{c}1 \mathrm{~mm}^{3} \text { isotropic, } \\
\mathrm{FOV}=180 \times 240 \times 240\end{array}$ & $\begin{array}{c}2 \mathrm{~mm}^{3} \text { isotropic, } \\
\text { FOV }=112 \times 112 \times 50 \text {, } \\
32-b 1000 \text {, and } 96- \\
\text { b3000, 8-b0 }\end{array}$ & Yes & $\begin{array}{c}3 \mathrm{~mm}^{3} \text { isotropic, } \\
\mathrm{FOV}=80 \times 80 \times 36 \times 300 \\
\mathrm{TE}=0.03, \mathrm{TR}=2\end{array}$ & Yes & \\
\hline EpiC & $\begin{array}{l}\text { 3T Philips } \\
\text { Achieva } \\
\text { TX }\end{array}$ & $78 / 1$ & $\begin{array}{c}1 \mathrm{~mm}^{3} \text { isotropic, } \\
\text { FOV }=176 \times 256 \times 265\end{array}$ & $\begin{array}{l}2 \mathrm{~mm}^{3} \text { isotropic, } \\
\mathrm{FOV}=128 \times 128 \times 50, \\
60-\mathrm{b} 2000 \text { and } 1-\mathrm{b} 0\end{array}$ & Yes & $\begin{array}{c}1.8 \times 1.8 \times 3 \mathrm{~mm}^{3} \\
\mathrm{FOV}=128 \times 128 \times 33 \times 200 \\
\mathrm{TE}=0.03, \mathrm{TR}=2\end{array}$ & & T1w/Flair \\
\hline $\begin{array}{c}\text { EpiC } \\
\text { longitudinal }\end{array}$ & $\begin{array}{l}\text { 3T Philips } \\
\text { Achieva } \\
\text { TX }\end{array}$ & $33 / 1$ & $\begin{array}{c}1 \mathrm{~mm}^{3} \text { isotropic, } \\
\mathrm{FOV}=176 \times 256 \times 265\end{array}$ & $\begin{array}{c}2 \mathrm{~mm}^{3} \text { isotropic, } \\
\text { FOV }=128 \times 128 \times 66 \\
60-\mathrm{b} 1000,60-\mathrm{b} 2000 \\
\text { and } 2-\mathrm{b} 0\end{array}$ & Yes & $\begin{array}{c}1.8 \times 1.8 \times 3 \mathrm{~mm}^{3} \\
\mathrm{FOV}=128 \times 128 \times 33 \times 200 \\
\mathrm{TE}=0.03, \mathrm{TR}=2\end{array}$ & & T1w/Flair \\
\hline$M S C$ & $\begin{array}{c}3 \mathrm{~T} \\
\text { Siemens } \\
\text { TRIO }\end{array}$ & $9 / 12$ & $\begin{array}{c}0.8 \mathrm{~mm}^{3} \text { isotropic, } \\
\text { FOV }=224 \times 256 \times 256\end{array}$ & & & $\begin{array}{c}4 \mathrm{~mm}^{3} \text { isotropic, } \\
\mathrm{FOV}=64 \times 64 \times 36 \times 818 \\
\mathrm{TE}=0.027, \mathrm{TR}=2.2\end{array}$ & & $\mathrm{~T} 1 \mathrm{w} / \mathrm{T} 2 \mathrm{w}$ \\
\hline$M I C s$ & $\begin{array}{c}3 \mathrm{~T} \\
\text { Siemens } \\
\text { Magnetom } \\
\text { prisma fit }\end{array}$ & $50 / 1$ & $\begin{array}{c}0.8 \mathrm{~mm}^{3} \text { isotropic, } \\
\text { FOV }=224 \times 320 \times 320\end{array}$ & $\begin{array}{c}1.6 \mathrm{~mm}^{3} \text { isotropic, } \\
\text { FOV=140x140x93, } \\
10-\mathrm{b} 300,40-\mathrm{b} 1000 \\
90-\mathrm{b} 2003-\mathrm{b} 0\end{array}$ & Yes & $\begin{array}{c}3 \mathrm{~mm}^{3} \text { isotropic, } \\
\mathrm{FOV}=80 \times 80 \times 48 \times 700 \\
\mathrm{TE}=0.03, \mathrm{TR}=0.6\end{array}$ & Yes & 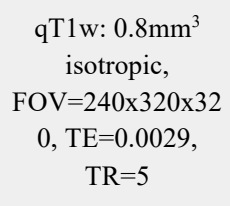 \\
\hline Audiopath & $\begin{array}{c}7 \mathrm{~T} \\
\text { Siemens } \\
\text { Magnetom }\end{array}$ & $10 / 1$ & $\begin{array}{c}0.6 \mathrm{~mm}^{3} \text { isotropic, } \\
\text { FOV }=256 \times 384 \times 384\end{array}$ & $\begin{array}{c}1 \mathrm{~mm}^{3} \text { isotropic, } \\
\text { FOV=200x200x132, } \\
66-\mathrm{b} 1000,66-\mathrm{b} 2000 \\
66-\mathrm{b} 3000,33-\mathrm{b} 0\end{array}$ & All & $\begin{array}{l}\text { data not processed } \\
\text { (cropped) }\end{array}$ & Yes & T1w/T2w?? \\
\hline
\end{tabular}

TAble S1. Evaluation datasets. For further details about the code used to run these datasets see micapipe.readthedocs/databases. The $\mathrm{T} 1 \mathrm{w} / \mathrm{T} 2 \mathrm{w}$ or Flair, the weighted image was calculated based on these structural acquisitions. FOV: field of view, TE: repetition time, TE: echo time, T1w: T1-weighted. 
bioRxiv preprint doi: https://doi.org/10.1101/2022 01.31.478189; this version posted February 2 , 2022. The copyright holder for this preprint (which was not certified by peer review) is the author/funder, who has granted bioRxiv a license to display the preprint in perpetuity. It is made available under aCC-BY 4.0 International license.

$\begin{array}{rccccccc}\text { Module/Dataset } & \text { MICs } & \text { EpiC } & \begin{array}{c}\text { EpiC } \\ \text { longitudinal }\end{array} & \text { Cam-Can } & \text { MSC } & \text { SUDMAX Audiopath } \\ \text { proc_structural } & 88 \pm 17 & 76 \pm 9 & 73 \pm 10 & 70 \pm 6 & 76 \pm 2 & 66 \pm 4 & 92 \pm 3 \\ \text { post_structural } & 125 \pm 14 & 44 \pm 10 & 46 \pm 14 & 51 \pm 7 & 135 \pm 20 & 44 \pm 4 & 227 \pm 22 \\ \text { proc_freesurfer } & 961 \pm 205 & p p & p p & p p & 815 \pm 88 & p p & 1154 \pm 104 \\ \text { GD } & 159 \pm 21 & 119 \pm 40 & 96 \pm 12 & 105 \pm 12 & 162 \pm 15 & 100 \pm 8 & 242 \pm 36 \\ \text { proc_dwi } & 246 \pm 37 & 63 \pm 15 & 114 \pm 15 & 41 \pm 5 & -- & 99 \pm 12 & 1104 \pm 274 \\ \text { SC } & 906 \pm 427 & 1364 \pm 498 & 1471 \pm 538 & 1086 \pm 387 & -- & 1652 \pm 776 & 910 \pm 399 \\ \text { proc_rsfmri } & 101 \pm 8 & 22 \pm 3 & 22 \pm 2 & 15 \pm 4 & 79 \pm 54 & 28 \pm 7 & \text { np } \\ \text { MPC } & 7 \pm 1 & 5 \pm 1 & 5 \pm 1 & 6 \pm 1 & 8 \pm 1 & -- & 9 \pm 2\end{array}$

TABLE S2. Processing times (shown as the mean \pm SD across subjects in minutes). $p \boldsymbol{p}$ : preprocessed, $\boldsymbol{n p}$ : not processed, --: No data available. The Morphology module took about 1 minute to process in all the databases. Multi-threaded processing is available only for ANTs and workbench functions. 


\begin{tabular}{|cccccccc} 
Dataset & MICs & EpiC & $\begin{array}{c}\text { EpiC } \\
\text { longitudinal }\end{array}$ & Cam-Can & MSC & SUDMEX & Audiopath \\
\hline anat & $401 \pm 16$ & $779 \pm 424$ & $326 \pm 72$ & $293 \pm 39$ & $89 \pm 181$ & $219 \pm 13$ & $591 \pm 68$ \\
\hline dwi & $3447 \pm 10$ & $2731 \pm 856$ & $1660 \pm 188$ & $726 \pm 105$ & 0 & $1126 \pm 374$ & $18480 \pm 1754$ \\
\hline func & $8647 \pm 498$ & $2221 \pm 633$ & $2034 \pm 945$ & $1949 \pm 297$ & $4867 \pm 3816$ & $3370 \pm 854$ & 0 \\
\hline xfm & $1474 \pm 69$ & $1123 \pm 52$ & $1114 \pm 135$ & $1014 \pm 30$ & $273 \pm 485$ & $901 \pm 25$ & $3840 \pm 374$ \\
\hline QC & $103 \pm 6$ & $37 \pm 20$ & $57 \pm 37$ & $46 \pm 13$ & 0 & $43 \pm 16$ & $106 \pm 41$ \\
\hline Total & $14072 \pm 599$ & $6891 \pm 1985$ & $5191 \pm 1377$ & $4028 \pm 484$ & $5229 \pm 4482$ & $5659 \pm 1282$ & $23017 \pm 2237$ \\
\hline
\end{tabular}

TABLE S3. Mean total size of the main directories by subject and database. The size of the directories is shown as mean and $\mathrm{SD}$ in Megabytes. The databases with modules that were not processed are shown as 0 . 
bioRxiv preprint doi: https://doi org/10.1101/2022 01.31.478189; this version posted February 2, 2022. The copyright holder for this preprint (which was not certified by peer review) is the author/funder, who has granted bioRxiv a license to display the preprint in perpetuity. It is made available under aCC-BY 4.0 International license.

\section{Database Topup Melodic FIX}

$\begin{array}{rcccccc}\text { CamCan } & \text { No } & \text { No } & \text { No } & \text { Yes } & \text { Yes } & \text { No } \\ \text { SUDMEX } & \text { Yes } & \text { No } & \text { No } & \text { Yes } & \text { Yes } & \text { No } \\ \text { EpiC } & \text { No } & \text { No } & \text { No } & \text { Yes } & \text { Yes } & \text { No } \\ \text { EpiC } & \text { No } & \text { No } & \text { No } & \text { Yes } & \text { Yes } & \text { No } \\ \text { longitudinal } & \text { No } & \text { No } & \text { No } & \text { Yes } & \text { Yes } & \text { No }\end{array}$

TABLE S4. rs- fMRI processing. Parameters used to process the rs-fMRI data. For details see micapipe.readthedocs/databases. 